\title{
Acquisition of a New-Latency Conditioned Nictitating Membrane Response-Major, but Not Complete, Dependence on the Ipsilateral Cerebellum
}

\author{
Christopher H. Yeo, ${ }^{1}$ Dominic H. Lobo, and Alison Baum
}

Neuroscience and Behaviour Group

Department of Anatomy and Developmental Biology

University College London

London WC1E 6BT, UK

\begin{abstract}
Classical conditioning of the nictitating membrane response (NMR) of rabbits is simple associative learning of a motor response. In several two-stage experiments, reversible inactivations of the deep cerebellar nuclei in stage 1 appeared to prevent acquisition of NMR conditioning in naive rabbits-no conditioned responses (CRs) were evident after inactivations were lifted in stage 2. Results of a three-stage experiment were different. When subjects were first trained with a light conditional stimulus (CS) in stage 1 , reversible cerebellar inactivations during conditioning to a different, tone CS during stage 2 did not appear to prevent new learning because CRs to the tone CS were evident when the inactivation was lifted. Results from the two-stage experiments support the suggestion that the cerebellum is essential for the acquisition of NMR conditioning, but results from the three-stage experiment do not. Here, we use a three-stage design with different interstimulus intervals (ISIs) in stages 1 and 2. Because CRs develop with latencies-to-peak dependent on the ISI, learning during stage 1 can be dissociated from that accruing in stage 2. Complete inactivation of the ipsilateral cerebellar nuclei with muscimol substantially but not completely prevented learning with the second ISI during stage 2 because small CR
\end{abstract}

${ }^{1}$ Corresponding author. peaks around the stage 2 ISI could be detected in some subjects after the inactivation had been lifted in stage 3 . We suggest that the weak levels of conditioning possible during unilateral inactivation depend on the contralateral cerebellum or on extracerebellar circuitry and that these may be capable of supporting transfer of conditioning in a previous three-stage experiment. But, we confirm that normal NMR conditioning is critically dependent on the ipsilateral cerebellum.

\section{Introduction}

The cerebellum is essential for normal classical conditioning of the eye-blink/nictitating membrane response (NMR) in rabbits-associative learning of a simple motor response. Lesions of the cerebellum and its associated circuitry abolish or impair conditioned responses (CRs) (for review, see Thompson 1986; Yeo 1987, 1991; Thompson and Krupa 1994). Our original lesion studies (Yeo et al. 1984, 1985b) identified lobule HVI of cerebellar cortex to be especially involved in the production of CRs. An anatomical analysis of HVI (Yeo et al. 1985c) indicated a convergence of conditioning-related information through mossy and climbing fiber inputs consistent with classical models that propose a motor learning role for the cerebellar cortex (Marr 1969; Albus 1971; Gilbert 1974, 1975; Ito 1982, 1989). Recent electrophysiological analysis has mapped eye-blink microzones in lobule HVI of cats, and stimulation of these areas disturbs significantly the production of conditioned, but not unconditioned, eye blinks (Hesslow 
1994a,b). Though these and many other experimental findings are consistent with the suggestion that there is neural plasticity essential for this learning within the cerebellum, they tell us little about its possible mechanism. Indeed, an alternative view is that cerebellar lesions do not damage stored motor memories but instead produce deficits only in the performance of conditioned responses (Bloedel and Bracha 1995; Llinas and Welsh 1993; Welsh and Harvey 1989, 1992).

Certainly, lesion studies alone cannot resolve whether the cerebellum actively contributes to the acquisition and storage of motor memories or whether it regulates learned movements stored in extracerebellar circuitry. Recent studies of eyeblink/NMR conditioning have addressed this problem using reversible lesion techniques. Conditioning trials can be given during functional inactivation of the cerebellum. If, after the inactivation is lifted, CRs are present, then they must have been formed during the inactivation, and it may be concluded that the cerebellum is not essential for acquisition of the learning. If CRs are not evident after the inactivation, then the cerebellum is implicated in the acquisition of conditioning-there may be essential plasticity within the cerebellum itself or in circuitry supplied by cerebellar output.

So far, evidence from different inactivation studies has been inconsistent. Welsh and Harvey (1991) used a three-stage experimental design. In stage 1 they conditioned to a light conditional stimulus (CS). Then, in stage 2, lidocaine was infused into the interpositus nucleus and all CRs to the light CS were blocked. During the lidocaine blockade, conditioning trials to a new, tone CS were given. In stage 3, after the blockade was lifted, CRs to both the light and the tone CRs were evident. It appeared that the lidocaine infusion had not prevented acquisition of learning to the tone CS.

In contrast, de novo conditioning to a tone CS appears to have been prevented using two-stage experimental designs. In such experiments, naive subjects receive conditioning trials during cerebellar inactivation. In stage 2 the inactivation is lifted and further test and conditioning trials are given. In the first of these two-stage experiments, the interpositus nucleus was inactivated using local cooling during conditioning trials with a tone CS. After the cold block was lifted, there was no evidence of CRs, but, with further training, conditioning developed at rates similar to those in naive animals (Clark et al. 1992). Infusion into the interpositus nucleus of the GABA-A agonist muscimol during conditioning trials with a tone CS produced identical results-no CRs were evident after the effects of the drug had worn off, and subsequent conditioning was at rates similar to those in naive animals (Krupa et al. 1993). Nordholm et al. (1993) found similar effects with lidocaine infusions at some locations in the cerebellar nuclei.

The later studies indicate an essential role for the cerebellum in NMR conditioning; the first study (Welsh and Harvey 1991) does not. Thompson and Krupa (1994) have suggested that the study by Welsh and Harvey suffers from two major weaknesses, which disallow a conclusion that the cerebellum has no role in the acquisition of NMR conditioning. First, the lidocaine infusions may have inactivated only cerebellar efferent fibers and spared activity in the cerebellar nuclei, allowing conditioning to proceed normally. Second, the apparent acquisition during nuclear inactivation in the Welsh and Harvey (1991) study might instead be transfer from the light CS used in stage 1 to the tone CS used in stage 2.

Both of these interpretations can be challenged. When cerebellar efferent fibers, rostral to the cerebellar nuclei in the brachium conjunctivum, are inactivated with tetrodotoxin, performance of CRs is prevented but learning can proceed normally (Krupa and Thompson 1995). In the Welsh and Harvey (1991) study, infusion cannula tip locations were in the dorsal aspect of the interpositus/dentate nuclei in five of the six subjects in the critical group, and distribution of the lidocaine was confirmed with autoradiography of $\left[{ }^{3} \mathrm{H}\right]$ lidocaine infusions. Very similar locations were identified as critical for learning in the two-stage experiment of Nordholm et al. (1993). So, there is little direct evidence to suggest that the lidocaine inactivated only efferent fibers in the Welsh and Harvey (1991) study, though this remains a possibility.

In studies of cross-modal transfer, initial training to a light CS facilitates subsequent conditioning to a tone CS and vice versa (Kehoe and Holt 1984; Schreurs and Kehoe 1987; Kehoe and Napier 1991). In these studies an important distinction is be made between "immediate" transfer (the appearance of CRs immediately upon unreinforced presentations of the second CS) and "general", transfer (more rapid conditioning to the second CS during reinforced presentations). Significantly, there is no immediate transfer from light to tone CSs (or from tone to light CSs) with NMR conditioning, but there is significant general transfer. In

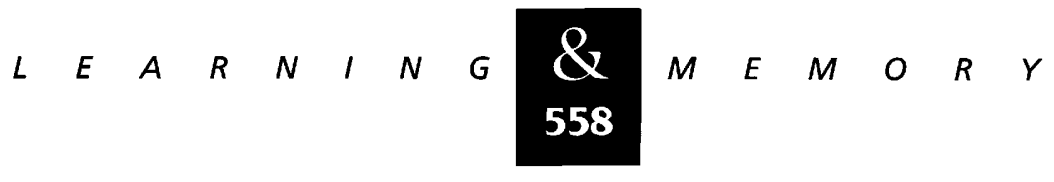


the Welsh and Harvey (1991) study, CRs were produced to unreinforced presentations of the second, tone CS after tone conditioning trials during the cerebellar inactivation. Because tone naive animals would not show such immediate transfer, there must have been some learning during the inactivation. Therefore, the inactivation may have been incomplete, or low levels of learning are possible during unilateral cerebellar inactivation. General transfer processes would have supported subsequent levels of conditioning during reinforced presentations of the tone CS.

Although the three-stage design of the experiment by Welsh and Harvey (1991) may suffer from the weakness that very low levels of learning during the cerebellar blockade might support transfer, the design has two major advantages. First, the efficacy of the inactivation can be monitored by occasional presentation of the previously conditioned, light CS. Second, any general deficits produced by cerebellar inactivation are controlled closely. If the inactivation resulted in any long-term impairments of function, then these would be revealed as impairments of CRs to the light CSconditioning that had been established before the lidocaine blockade. No such deficits were seen in the study by Welsh and Harvey, but the two-stage experiments by Clark et al. (1992), Krupa et al. (1993), and Nordholm et al. (1993) cannot test for them. The possibility that long-term inactivation of the cerebellum may have resulted in longer term functional impairments, such as the down-regulation of GABA receptors, cannot be excluded. Krupa et al. (1993) used high doses $(15 \mu$ moles) of muscimol for 4 consecutive days-such doses produce inactivation of the cerebellar nuclei that far outlast the duration of the conditioning session. The absence of CRs after conditioning during muscimol inactivation might relate to longer term effects of muscimol.

We have resolved one of these problems by inactivating the cerebellar nuclei during extinction training (Ramnani and Yeo 1996). After initial acquisition training, extinction training was given during inactivation of the cerebellar nuclei using low doses of muscimol $(1.5 \mu$ moles) sufficient to block the production of all CRs. After the effects of the drug had worn off, there remained bigh levels of CRs consistent with the suggestion that there was no extinction learning under the blockade and guaranteeing that there were no general performance deficits owing to prolonged use of muscimol. In a related study (Hardiman et al. 1996) we demonstrated first that acquisition and then extinction behaviors were prevented by muscimol inactivation of the cerebellar nuclei in the same subjects. Because postextinction training performance deficits could again be ruled out, there would have been no similar deficits after the acquisition training. Our findings are consistent with real impairments of acquisition and extinction learning.

The possibility that the apparent high levels of learning under lidocaine blockade in the threestage study by Welsh and Harvey (1991) was really immediate transfer between the two CSs, supported by very low levels of conditioning under the blockade, has not been tested formally. A particular difficulty with this three-stage design is to distinguish between conditioning that had developed to the different CSs. The CS-unconditioned stimulus (US) interval was similar for the light and tone CSs; so CRs to both stimuli were very similar in their topography. In the present study we describe two experiments with three-stage designs modified to enable conditioning before inactivation to be dissociated from any conditioning that might develop during inactivation. The experimental designs take advantage of the timing of conditioned NMRs as in the transfer study by Kehoe and Napier (1991). In well-trained subjects, conditioned movements of the NM are accurately timed such that their peak excursion coincides with delivery of the periocular stimulation (Smith 1968; Mauk and Ruiz 1992). This precise timing underlines the adaptive value of CRs. In experiment 1 , control and experimental rabbits were trained to a tone CS using a standard delay conditioning protocol with a short interstimulus interval (ISI) of 250 msec in stage 1 . This procedure results in CRs with latencies-to-peak that closely match the ISI. In stage 2 , control subjects were then trained with the same tone CS but with a longer ISI of $650 \mathrm{msec}$ to produce new, longer latency CRs and extinction of the short-latency CRs. Experimental subjects received infusions of muscimol in the cerebellar nuclei during identical conditioning with the longer ISI. In stage 3, after the effects of the drug had dissipated, the experimental subjects were tested to reveal their CR latencies. Exclusively short-latency responses would indicate that there was no learning during the inactivation, but high-amplitude long-latency responses would be consistent with considerable learning under the inactivation. A mixture of response types might indicate that there are low levels of learning under the inactivation capable of supporting transfer in the study by

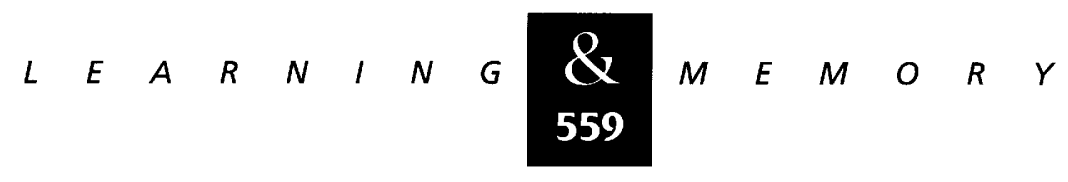


Yeo et al.

Welsh and Harvey (1991). In experiment 2, the longer ISI was trained in stage 1 and the shorter ISI was trained in stage 2 , to counterbalance any possible differential effects of muscimol on long- and short-latency CRs.

\section{Experiment 1}

\section{Materials and Methods}

\section{SUBJECTS}

The subjects were 21 male, Dutch belted rabbits weighing between $1.7 \mathrm{~kg}$ and $2.4 \mathrm{~kg}$. They were individually housed with free access to food and water and maintained on a 12-hr light-dark cycle.

\section{EXPERIMENTAL PROTOCOLS}

\section{(1) EXPERIMENTAL DESIGN}

There were three experimental groups (see Table 1). Group C subjects were normal controls, group PM subjects had an infusion guide cannula implanted in the dorsal aspect of the paramedian lobe, and group IP subjects had an infusion guide cannula implanted close to the interpositus nucleus of the cerebellum. The experiment was in three stages. In stage 1, all subjects received four, daily sessions of delay NMR conditioning with an
ISI of $250 \mathrm{msec}$ (sessions 1-4). On the following day, subjects in all groups began stage 2 that consisted of four, daily conditioning sessions (sessions 5-8) with an ISI of 650 msec. Subjects of groups PM and IP received muscimol infusions before each conditioning session. All subjects were then rested for 3 days. On the next day, in stage 3 , subjects in all groups received 10 unpaired presentations of the CS alone (10-unpaired session), and they then started four, daily conditioning sessions with an ISI of $650 \mathrm{msec}$ (sessions 9-12).

Acquisition of a short-latency NMR by all groups was tested in stage 1. Acquisition of the longer latency response was tested in stage 2 for the control group C and for group PM with muscimol infusion in an area of cerebellum that is not critical for production of CRs (Yeo et al. 1985b). Muscimol infusions directed at the interpositus nucleus in group IP should prevent the appearance of all CRs. Full acquisition during muscimol blockade of the cerebellar nuclei during stage 2 in this group would be revealed by the presence of longer latency responses in the 10-unpaired session and in the early parts of stage 3 , comparable with similar sessions in groups C and PM. Complete blockade of acquisition, without long-term damage to the cerebellar circuitry, would be revealed by exclusively short-latency responses in the 10-unpaired session and in the early parts of stage 3 . Low levels of acquisition during muscimol blockade would be revealed by the presence of low-amplitude, longlatency responses together with short-latency responses in the 10-unpaired session and early stage 3 trials.

Table 1: Experiment 1-experimental design

\begin{tabular}{|c|c|c|c|c|c|}
\hline \multirow[b]{2}{*}{ Experiment 1} & \multirow{2}{*}{$\frac{\text { Stage } 1}{\text { sessions } 1-4}$} & \multirow{2}{*}{$\frac{\text { Stage } 2}{\text { sessions } 5-8}$} & \multirow{2}{*}{$\begin{array}{l}\text { Interval } \\
3 \text { days }\end{array}$} & \multicolumn{2}{|c|}{ Stage 3} \\
\hline & & & & 10 unpaired & Sessions $9-12$ \\
\hline $\begin{array}{l}\text { Group C } \\
\text { nonoperated control } \\
(n=4)\end{array}$ & $\begin{array}{l}\text { conditioning } \\
\text { ISI } 250 \text { msec }\end{array}$ & $\begin{array}{l}\text { conditioning } \\
\text { ISI } 650 \mathrm{msec}\end{array}$ & & $\begin{array}{c}10 \mathrm{CS} \\
710 \mathrm{msec}\end{array}$ & $\begin{array}{l}\text { conditioning } \\
\text { ISI } 650 \mathrm{msec}\end{array}$ \\
\hline $\begin{array}{l}\text { Group PM } \\
\text { paramedian lobe cannula } \\
(n=5)\end{array}$ & $\begin{array}{l}\text { conditioning } \\
\text { ISI } 250 \text { msec }\end{array}$ & $\begin{array}{l}\text { conditioning } \\
\text { ISI } 650 \text { msec } \\
\text { Muscimol } \\
\text { (see Table 2) }\end{array}$ & & $\begin{array}{c}10 \mathrm{CS} \\
710 \mathrm{msec}\end{array}$ & $\begin{array}{l}\text { conditioning } \\
\text { ISI } 650 \mathrm{msec}\end{array}$ \\
\hline $\begin{array}{l}\text { Group IP } \\
\text { interpositus nucleus cannula } \\
(n=5)\end{array}$ & $\begin{array}{l}\text { conditioning } \\
\text { ISI } 250 \mathrm{msec}\end{array}$ & $\begin{array}{l}\text { conditioning } \\
\text { ISI } 650 \text { msec } \\
\text { Muscimol } \\
\text { (see Table 2) }\end{array}$ & & $\begin{array}{c}10 \mathrm{CS} \\
710 \mathrm{msec}\end{array}$ & $\begin{array}{l}\text { conditioning } \\
\text { ISI } 650 \text { msec }\end{array}$ \\
\hline
\end{tabular}

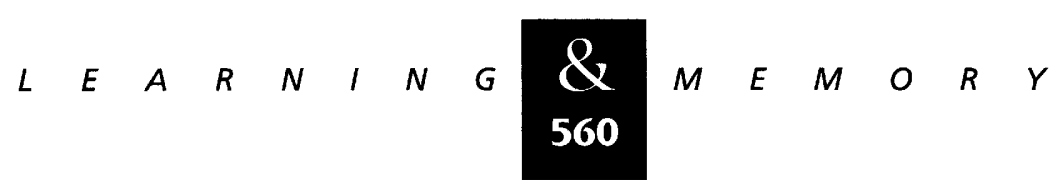


Subjects were admitted to the IP group only if muscimol completely prevented expression of CRs during stage 2. Any interpositus cannulated subjects that produced 5\% or more CRs (see below) at any latency during any session in stage 2 were not admitted to the IP group. Subjects that give CRs on some sessions in stage 2 but not on others were likely to have had inconsistent infusion of muscimol and were excluded from the study. The level of responses given by subjects in the IP and PM groups was used to assess the spread of the muscimol infusion in the cerebellar cortex.

\section{(2) NMR CONDITIONING PROCEDURE}

The conditioning apparatus and procedures are based on those developed by Gormezano et al. (1962) and on those described in an earlier paper (Yeo et al. 1985a). Briefly, the subjects were placed in sound-attenuating chambers and movement of the nictitating membrane was transduced using a low-torque potentiometer. We recorded movements of the nictitating membrane on both sides in all animals, and we used an isotonic transducer. The nictitating membrane was coupled to a lever on the shaft of the potentiometer through a miniature universal joint. This arrangement provides isotonic transduction without the need for a restoring force acting on the transduced movement and is based on the design of Gormezano and Gibbs (1988). The measurements we made are, therefore, directly comparable with those of Welsh and Harvey $(1989,1991)$ and those in our more recent studies (Yeo and Hardiman 1992; Gruart and Yeo 1995; Hardiman et al. 1996; Ramnani and Yeo 1996) but differ from other studies that use counterbalanced transducers. The output from the movement transducer was fed to a 12-bit A-D convertor (CED 1401) and sampled at $1 \mathrm{kHz}$. The resolution of this system was $0.03 \mathrm{~mm}$. Amplitudes and frequencies of responses were calculated on-line. The digitized waveform of each individual trial was also stored for additional off-line analyses.

Monofilament suture loops were placed in the nictitating membrane on both sides under local anesthesia. After $4 \mathrm{hr}$, movement transducers were attached to the NM sutures and the subjects were placed in their restraining boxes within the condi- tioning chambers for a 1-hr habituation session. Stage 1 began the next day.

In stage 1 , all subjects received daily conditioning sessions with the US applied to the right side. Each session contained 90 paired CS-US trials and 10 unpaired CS-alone trials. The CS was a 310msec duration, $1-\mathrm{kHz}$ sine wave tone of $90 \mathrm{~dB}$ (A scale) intensity. During conditioning sessions, the CS was paired with a periorbital, $60-\mathrm{msec}$ train of three biphasic electrical pulses of $2.0-\mathrm{mA}$ intensity as the US. Typically, this US yields URs with amplitudes of 6-7 $\mathrm{mm}$. The CS-US interval was 250 msec, and the 60-msec US was coterminous with the CS. Each daily session was of 100 trials with a mean intertrial interval of $30 \mathrm{sec}$, randomized between 25 and 35 sec. Every tenth presentation of the CS was unpaired with the US. During these and all other trials, NM position was monitored for 550 msec before and $1450 \mathrm{msec}$ after CS onset. Hence, in the CS-alone trials, long latency CRs could be detected and analyzed. For CR frequency analysis, responses of $0.5 \mathrm{~mm}$ or greater following CS onset and with onsets between 35 and $1000 \mathrm{msec}$ after CS onset were defined as CR (see Gruart and Yeo 1995).

Stage 2 followed on the next day. It consisted of four, daily conditioning sessions. The CS was the same $1-\mathrm{kHz}$ tone stimulus, but its duration was 710 msec and the ISI was $650 \mathrm{msec}$. In all other details, the procedures were as in stage 1 . Each subject in the PM and IP cannulated group received an infusion of muscimol $1 \mathrm{hr}$ before the session began. For IP group subjects, each infusion was either 7.7 nmoles or 11.55 nmoles of muscimol ( 1 or $1.5 \mu$ of 7.7-mmole solution, muscimol hydrobromide) over 1 min (see Table 2 for full details and one exception). Any subjects with interpositus nucleus cannulae that gave CRs were later rejected from the study (see below). The PM group subjects all received a single infusion of 11.55 nmoles of muscimol ( $1.5 \mu \mathrm{l}$ of $7.7-$ mmole solution), $1 \mathrm{hr}$ before the conditioning session on each day (see Table 2 for full details and one exception).

The 10-unpaired session was given on the fourth day after the last session of stage 2 . It consisted of 10 presentations of the tone CS, duration $710 \mathrm{msec}$ as in stage 2 . Other details were as in stage 1 .

Stage 3 began immediately after the 10 unpaired session. It consisted of four, daily conditioning sessions with an ISI of $650 \mathrm{msec}$. In all details, it was as in stage 2 except that there were no muscimol infusions.

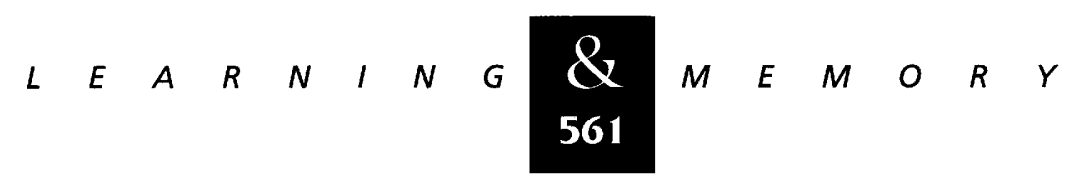


Yeo et al.

Table 2: Experiment 1-muscimol dose for each cannulated subject

\begin{tabular}{lccccc}
\hline Experiment 1 & Subject & $\begin{array}{c}\text { Session 5 } \\
\text { (nmoles) }\end{array}$ & $\begin{array}{c}\text { Session 6 } \\
\text { (nmoles) }\end{array}$ & $\begin{array}{c}\text { Session 7 } \\
\text { (nmoles) }\end{array}$ & $\begin{array}{c}\text { Session 8 } \\
\text { (nmoles) }\end{array}$ \\
\hline Group PM & PM1 & 11.55 & 11.55 & 11.55 & 11.55 \\
& PM2 & 11.55 & 11.55 & 11.55 & 11.55 \\
& PM3 & 11.55 & 11.55 & 11.55 & 11.55 \\
& PM4 & 11.55 & 11.55 & 11.55 & 11.55 \\
Group IP & PM5 & 11.55 & 11.55 & 11.55 & 11.55 \\
& IP1 & 7.7 & 11.55 & 11.55 & 11.55 \\
& IP2 & 7.7 & 11.55 & 11.55 & 11.55 \\
& IP3 & 7.7 & 7.55 & 7.7 & 7.7 \\
\hline IP4 & 7.7 & 7.7 & 7.7 & $15.4^{*}$ \\
\hline
\end{tabular}

In two instances $\left({ }^{*}\right)$ a CR was produced to the first CS of session 8 . In these cases, we suspect that the first, 1- $\mu$ l infusion did not penetrate gliosis around the cannula guide tip. The subjects were removed from the session, and a further 7.7 nmoles was given ( $1 \mu \mathrm{l}$ of a $7.7-$ mmole solution), $0.5 \mathrm{~mm}$ deeper. After an additional 1-hr wait, the conditioning session commenced.

\section{DATA ANALYSIS}

CR FREQUENCY, GROUP ASSIGNMENT, AND ESTIMATION OF THE SPREAD OF MUSCIMOL

CR frequency, the usual measure of NMR conditioning was used only to verify the subjects' group assignment in this study. NMRs achieving an amplitude criterion of $\geqslant 0.5 \mathrm{~mm}$ and with true onset latencies within 35-1000 msec after CS onset were deemed to be CRs, consistent with most other studies. All IP group subjects showed $\$ 5 \%$ CRs in any session of stage 2 .

The total number of CRs in stage 2 for all subjects in the IP and PM groups was calculated and was correlated with the distance of the cannula tip from the dorsolateral anterior interpositus nucleus (see below).

AMPLITUDE MEASUREMENT OF SHORT- AND LONG-LATENCY CRS, T1 AND T2

Conditioning should produce CRs timed such that their peak amplitudes occur at around the delivery of the US. So, in stage 1 , CR peak amplitude should be $\sim 250 \mathrm{msec}$, and in stages 2 and 3, CR peak amplitude should be $-650 \mathrm{msec}$. To assess the level of learning accruing from conditioning at the different ISIs, two time windows, T1 and T2, were set around these latencies (see Fig. 1). T1 extended from $200 \mathrm{msec}$ to $350 \mathrm{msec}$ after CS on- set; T2 extended from $500 \mathrm{msec}$ to $850 \mathrm{msec}$ after CS onset. ${ }^{1}$ The maximum NM excursion, from a pre-CS baseline level, was measured within the T1 and $\mathrm{T} 2$ windows for every unpaired $\mathrm{CS}$ trial on every session as a measure of response strength around the two latencies. These measures were the T1 Amplitude and the T2 Amplitude. For each conditioning session there were $10 \mathrm{~T} 1$ and $10 \mathrm{~T} 2 \mathrm{am}-$ plitudes-these were averaged to produce session mean T1 and T2 amplitudes for each group.

The arithmetic difference (T1 - T2) between the NMR amplitudes in each time window is a convenient single-measure indication of the relative strength of conditioning to the short and long ISIs. $\mathrm{T} 1$ - T2 values were calculated for each trial and then averaged to produce mean $\mathrm{T} 1-\mathrm{T} 2$ values for every subject on each session. Group differences were tested with two-way, repeated-measures ANOVA followed by Student-Newman-Keuls post hoc tests. Group session T1, T2, and T1 - T2 means were plotted graphically.

Data from the 10-unpaired session were treated to produce similar $\mathrm{T} 1, \mathrm{~T} 2$, and $\mathrm{T} 1-\mathrm{T} 2$ measures for each subject on each of the 10 test

${ }^{1}$ Data from experiments 1 and 2, where naive subjects were initially conditioned with ISIs of $250 \mathrm{msec}$ or $650 \mathrm{msec}$, respectively, were used to set the $\mathrm{T} 1$ and $\mathrm{T} 2$ time windows. A target was set such that $>90 \%$ of CR peaks should fall within the appropriate time window. CR peaks $(96.6 \%)$ fell within window T1 for all CRs within sessions 1-4 of experiment 1, and $92.2 \%$ of CR peaks fell within window T2 for sessions $1-4$ of experiment 2 .

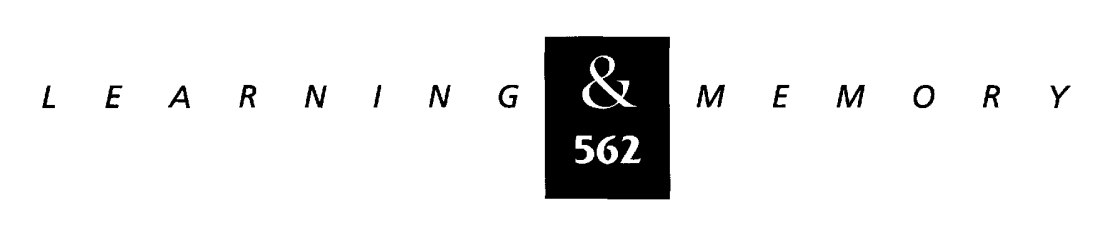




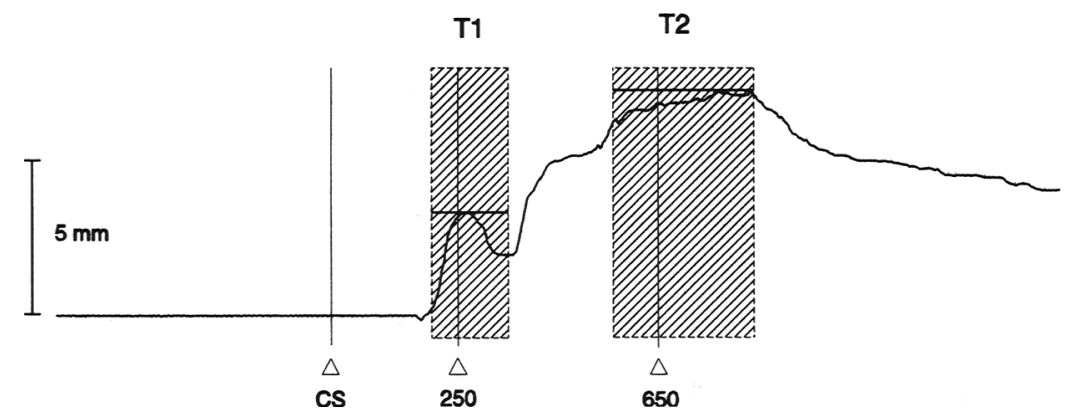

Figure 1: A single NM CR waveform from a CS-alone (unpaired) trial of a representative subject from group $C$ (subject $\mathrm{C} 1$, experiment 1, 10-unpaired session). The subject had been conditioned with an ISI of $250 \mathrm{msec}$ in stage 1 and then with an ISI of $650 \mathrm{msec}$ in stage 2. The CS onset (CS) is shown as a solid line; the previous and current CS-US intervals (250 msec and $650 \mathrm{msec}$ ) are shown by broken lines. Two time windows (T1 and $\mathrm{T} 2$ ), each of 150-msec duration, straddle the two US presentation periods and are shown hatched. T1 extends from 200 to $350 \mathrm{msec}$ and $\mathrm{T} 2$ extends from 600 to 750 msec after CS onset. The horizontal bar in each time window indicates the maximum NM excursion from a pre-CS baseline level. These maxima give the $\mathrm{T} 1$ and $\mathrm{T} 2$ peak amplitudes. Calibration bar, $5 \mathrm{~mm}$. trials. Group differences were tested with one-way ANOVA on subject T1 - T2 trial means followed by Student-Newman-Keuls post hoc tests. The $\alpha$ level for significance was $P<0.05$ throughout. Group trial T1, T2, and T1 - T2 means were plotted graphically.

We also used signal averaging (SigAvg, CED) to produce session-average NMR wave forms from the unpaired CS trials. These are presented to display the full topography of NMRs throughout the experiment.

\section{SURGERY}

The methods for locating the cerebellar nuclei and implanting cannula in rabbits for the IP group are as described previously (Hardiman et al. 1996; Ramnani and Yeo 1996). Subjects were anesthetized using a fentanyl, fluanisone mixture (Hypnorm, Janssen; $0.1 / 5.0 \mathrm{mg} / \mathrm{kg}$, i.m.) with a supplement of benzodiazepam (Valium, Roche; $0.5 \mathrm{mg}$ / kg, i.v.). Each subject was then intubated with an endotracheal tube, and the head was placed in a stereotaxic instrument (Kopf). Naloxone hydrochloride (Narcan, DuPont; 5-7 $\mu \mathrm{g} / \mathrm{kg}$, i.v.) was used to antagonize the fentanyl, and anesthesia was maintained throughout the operation using halothane in a nitrous oxide/oxygen mixture. The scalp was reflected and bone and dura removed to expose the right cerebellar cortex. The cerebellar nuclei were identified by their coordinates mea- sured from $\lambda$ and by electrophysiological recording. We looked for rapid cellular activity 1-2 mm below the deepest cortical layer ventral to the rostromedial part of the paramedian lobe. We then searched for an eye-blink-related area in the deep nuclei. Microelectrode tracks at $0.5-\mathrm{mm}$ horizontal separations were made until cellular activity that correlated with blinks evoked by gentle tactile stimulation of the cornea and periocular area was recorded. To evoke blinks while recording, we maintained a level of anesthesia that completely suppressed the toe-pinch response but that did not entirely suppress the corneal blink reflex. A sterilized 24-guage stainless steel cannula guide with a threaded nylon boss was then implanted $1 \mathrm{~mm}$ caudal and $1 \mathrm{~mm}$ dorsal to the position of the activated cells. The placement of the guide tip avoided damage to the connections of these cells, and the orientation of the guide avoided damage to parts of the overlying cortex that are important for NMR conditioning (Yeo et al. 1984, 1985b). Exposed brain was covered with sterile absorbable gelatin foam, and the cannula guide boss was fixed to the skull with dental cement. The scalp was sutured around the cannula guide, and the animal was removed from the stereotaxic instrument. A sterilized blanking wire with a nylon cap sealed the implanted guide. The animal was given buprenorphine (Temgesic, $100 \mu \mathrm{g} /$ day) and chloramphenicol (chloramphenicol succinate, $30 \mathrm{mg} /$ day) b.i.d. for 3 days. All cannulated rabbits were allowed 2 weeks for recovery.

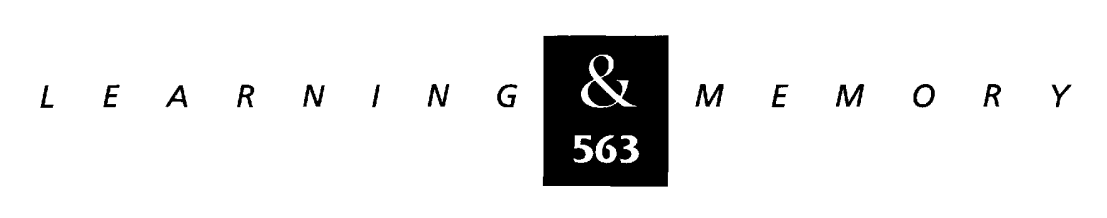


Yeo et al.

Rabbits for the PM group were treated similarly except that no electrophysiological recordings were made and the guide cannula was placed, under visual guidance, $1.5 \mathrm{~mm}$ below the surface of the paramedian lobe, $\sim 1 \mathrm{~mm}$ caudal to the IP group placements.

\section{MUSCIMOL INFUSION}

One hour before each training session within stage 2, subjects in the PM and IP groups received muscimol infusions. The sealing cap with blanking wire was removed from the guide cannula and replaced with a $36 \mathrm{G}$ cannula that protruded $0.5 \mathrm{~mm}$ below the end of the guide cannula. Muscimol solution (see Table 1 for concentrations and volumes) was infused at $0.3 \mu \mathrm{l} / \mathrm{min}$. The injection cannula was then withdrawn after a further $1 \mathrm{~min}$, and the blanking wire was replaced. The subjects then rested for $1 \mathrm{hr}$ before conditioning began.

\section{HISTOLOGY}

At the conclusion of all conditioning, the rabbits were terminally anesthetized with pentobarbitone sodium. They were then perfused through the aorta with $0.9 \%$ saline followed by $4 \%$ formaldehyde. The guide cannulae were removed. The brains were dissected free from the skull, embedded in gelatin, and stored in formol-sucrose solution. The brains were frozen and serially sectioned transversely at $60 \mu \mathrm{m}$. Sections were mounted and stained for Nissl substance with cresyl fast violet.

The sections were examined under the microscope. The location of the tip of each cannula was noted and also the location and extent of incidental damage. The cannula tip locations were reconstructed on a standard series of transverse sections previously prepared from three other brains that had been sectioned in the stereotaxic plane and stained with cresyl violet for Nissl substance and with luxol fast blue for myelin (Yeo et al. 1985b). The anatomy of the cerebellum of Dutch rabbits is quite consistent and allows reconstruction of the cannula tip positions using folial and nuclear landmarks.

For each subject in the IP and PM groups, the section containing the location of the cannula tip was selected This location was measured in cartesian coordinates relative to the midline point at the base of the brain. A further section, containing an area of dorsolateral anterior interpositus/medial dentate nucleus, where lesions are known to be effective in abolishing CRs, was selected, and the coordinates of that nuclear area were measured relative to the midline base of the brain stem. Our estimated accuracy in determining a critical area in the interpositus nucleus is $0.5 \mathrm{~mm}$. The number of intervening sections multiplied by the section thickness $(60 \mu \mathrm{m})$ gave the horizontal distance between the two points, and the minimum distance between the cannula tip and the dorsolateral anterior interpositus was calculated using trigonometry.

\section{Results}

The principal finding was that unilateral inactivation of the deep cerebellar nuclei substantially impaired but did not completely prevent acquisition of a new latency CR.

\section{VERIFICATION OF CANNULA PLACEMENTS AND GROUP ASSIGNMENT}

There were five subjects in control group C. Seven subjects were implanted with a cannula directed at the interpositus nucleus. Of these, five satisfied the criteria for inclusion in the IP group. The locations of the cannula tips are shown in Figure 2. All are close to the anterior interpositus nucleus. The two excluded subjects gave CRs erratically during stage 2 and were deemed to have had faulty infusions of muscimol on one or more sessions. Eight subjects were implanted with cannulae at various distances from the anterior interpositus nucleus in different parts of the paramedian lobe. Of these, three were rejected because their CRs and unconditioned responses (URs) in stage 1 were of low and erratic amplitudes. Five implanted subjects satisfied our criteria for inclusion in the PM group; they had cannula tip placements at various locations in the dorsal part of paramedian lobe as shown in Figure 2.

ACQUISITION OF SHORT- AND LONG-LATENCY CRS

STAGE 1

All subjects in all groups acquired CRs during stage 1 training with a $250-\mathrm{msec}$ ISI. Signal-averaged response waveforms of a representative example from groups C, IP, and PM are shown in Figure 3. CRs developed with a latency-to-peak of $\sim 260$ msec. CR amplitudes declined within $\sim 300$

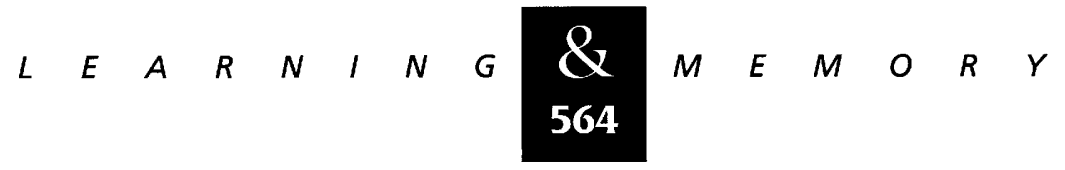




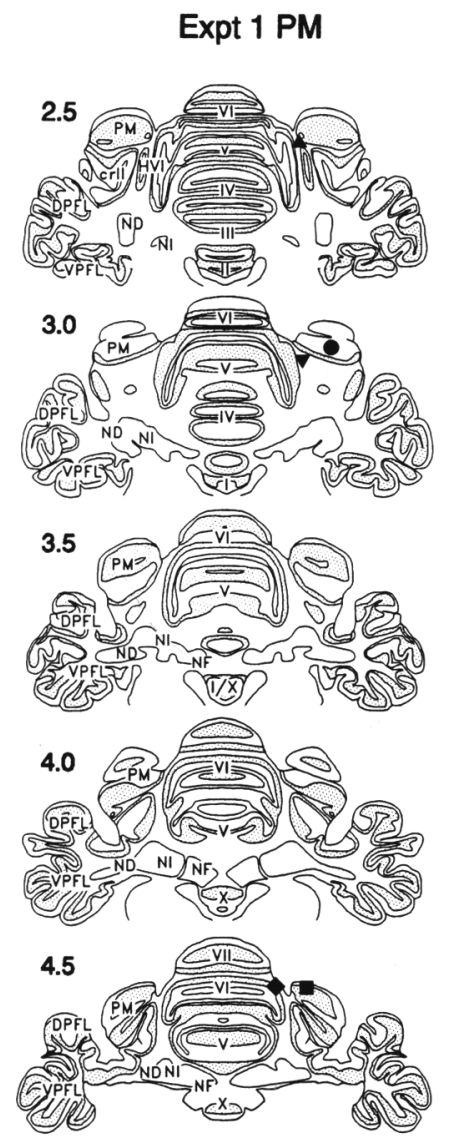

Expt 1 IP

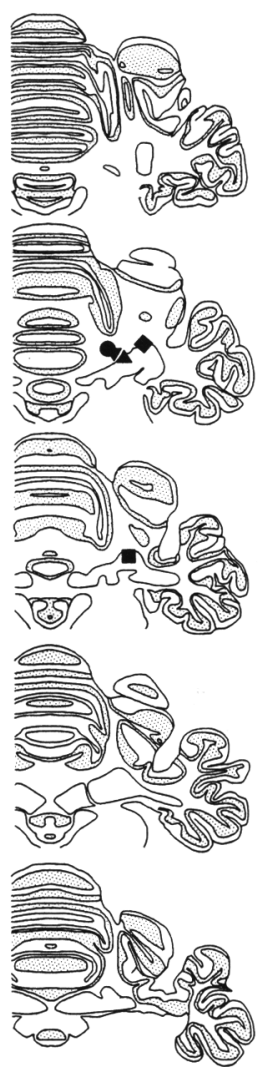

msec from their peak, so that NM excursions at $\sim 650 \mathrm{msec}$ were slight.

Amplitude analysis within the $\mathrm{T} 1$ and $\mathrm{T} 2$ windows is completely consistent with the picture presented by signal averaging (see Fig. 4). Groups $\mathrm{C}$ and PM developed CRs with T1 amplitudes of $\sim 5$ mm by session 4. Group IP T1 amplitudes were slightly lower at $\sim 3.5 \mathrm{~mm}$, but in all groups, T1 amplitudes were clearly greater than T2 amplitudes. Two-way, repeated-measures ANOVA of T1 - T2 revealed no significant differences between groups over sessions $1-4[F(2,13)=0.598$, $P>0.05]$.

\section{STAGE 2}

In group C subjects, conditioning with an ISI of $650 \mathrm{msec}$ quickly increased the amplitude of responses in T2, whereas $\mathrm{T} 1$ amplitudes declined more slowly. By session $6, \mathrm{~T} 1$ and $\mathrm{T} 2$ amplitudes were similar, and by session $8, T 2$ amplitudes were substantially greater as $\mathrm{T} 1$ responses extinguished. By the end of stage 2, group $\mathrm{C}$ had reversed their stage 1 response behavior. This reversal is clearly
Expt 2 IP

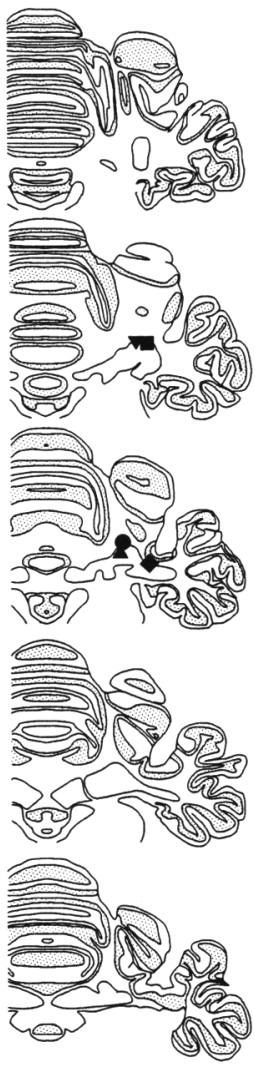

Figure 2: Reconstructions of cannula tip positions on a standard series of transverse sections at $0.5-\mathrm{mm}$ intervals through the cerebellar nuclei from 2.5 $\mathrm{mm}$ to $4.5 \mathrm{~mm}$ caudal to $\lambda$. Each subject is identified by a different symbol. Experiment 1 PM: (PM1) $\mathbf{\nabla}$; (PM2) $\mathbf{\Delta}$; (PM3) $($ PM4) $\mathbf{\square}$; (PM5) $\bullet$. Experiment 1 IP: (IP1) $\boldsymbol{\nabla} ;$ (IP2) $\mathbf{\Delta} ;($ IP3) $;($ IP4) $\mathbf{\square}$; (IP5) $\bullet$. Experiment 2 IP: (IP1) $\mathbf{\nabla}$; (IP2) $\mathbf{\Delta}$; (IP3) (IP4) $\mathbf{\square}$; (IP5) . Abbreviations: (crll) crus II of the ansiform lobe; (DPFL) dorsal paraflocculus; (HVI) hemispheral lobule $\mathrm{VI}$; (ND) dentate nucleus; (NF) fastigial nucleus; (NI) interpositus nucleus; (PM) paramedian lobe; (VPFL) ventral paraflocculus; (I-X) lobules I-X of the vermis. seen in the T1 - T2 plots in Figure 4, where group $C$ response differences fall from $+5 \mathrm{~mm}$ to $-2 \mathrm{~mm}$. The increase in longer latency response amplitudes with a decrease in shorter latency responses is also seen clearly in Figure 3.

In group PM subjects, $\mathrm{T} 1$ and $\mathrm{T} 2$ amplitudes were similar in session 5 , and then T2 amplitudes increased over sessions 6-8. Overall, group PM was similar to group $\mathrm{C}$ but response amplitudes were slightly lower. Muscimol infusion in the paramedian lobe produced small impairments in CR amplitude but neither impaired expression and acquisition of longer latency CRs nor extinction of shorter latency CRs. The T1 - T2 amplitude plot (Fig. 4) reveals that PM group subjects learned the T1-T2 reversal slightly more quickly than control group C subjects.

Group IP subjects were selected for full inactivation during stage 2 , and so their $\mathrm{T} 1$ and $\mathrm{T} 2$ amplitudes were at baseline levels.

10-UNPAIRED SESSION

On the fourth day after session 8,10 unpaired

$$
\cdots \cdots, \mathbf{E}
$$


Yeo et al.

Figure 3: Signal-averaged, NM-conditioned response waveforms of all 10 unpaired trials in each session from a representative subject in each group in experiments 1 and 2. Experiment 1: Control subject is $\mathrm{C1}$; PM cannula subject is PM5; IP cannula subject is IP2. Experiment 2: Control subject is C2; IP cannula subject is IP5. The solid line represents the CS onset (CS), and the broken lines represent the two ISIs of 250 and 650 msec.

\section{Experiment 1}
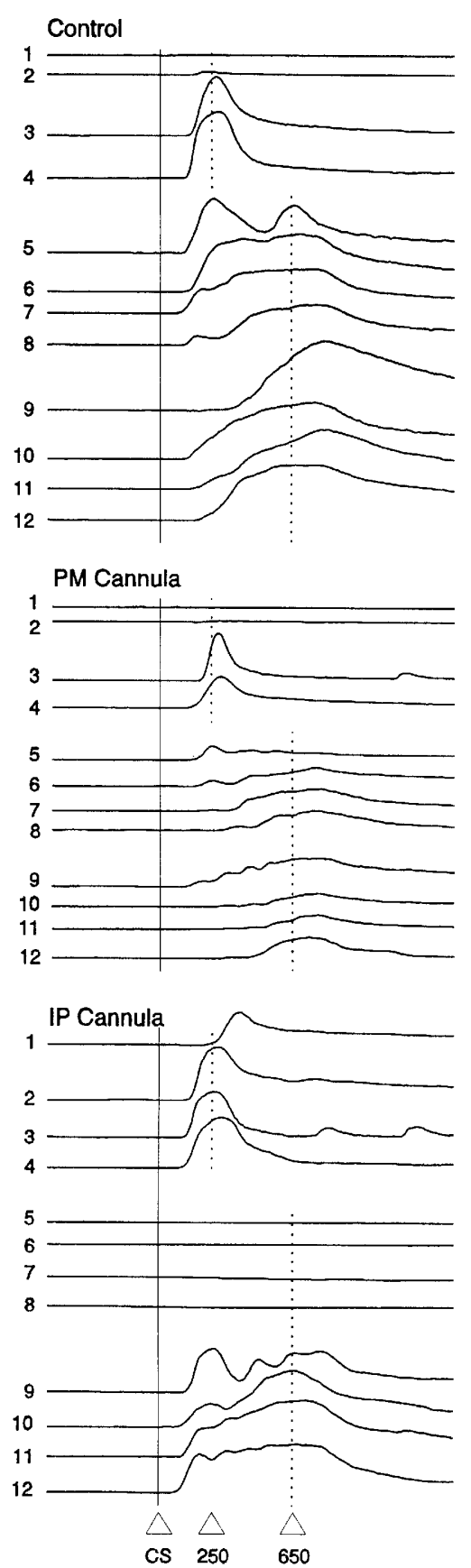

\section{Experiment 2}
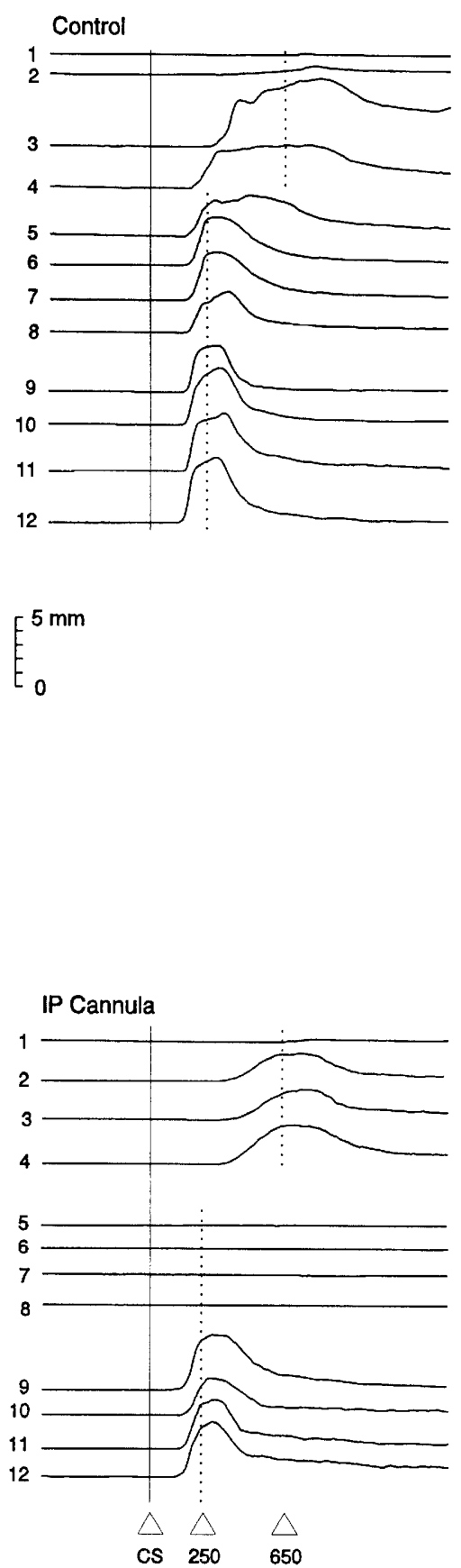

presentations of the CS revealed CR topographies before commencing conditioning in stage 3 . This was the critical test for determining whether group IP had learned during muscimol inactivation in stage 2 .

Control group $\mathrm{C}$ showed good retention from session 8 , with all $\mathrm{T} 2$ amplitudes greater than $\mathrm{T} 1$ amplitudes. Figure 5 shows the 10-unpaired-ses- sion, signal-averaged responses for each subject. Short-latency responses were not depressed completely, and so the onset latencies for the complete response were similar to those in stage 1 , but there was considerable development of the response at $\sim 650 \mathrm{msec}$. Subjects C1, C4, and C5 showed some segmentation of the CR. Small oscillations of movement intervened between response onset and

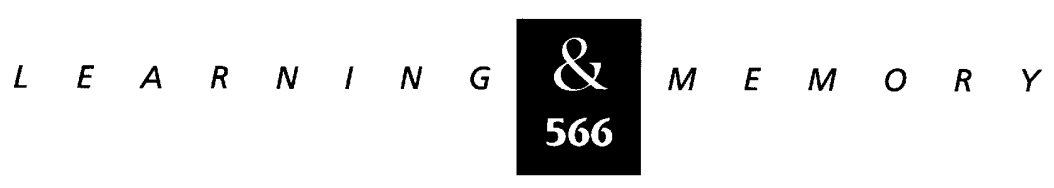


Control, T1 \& T2

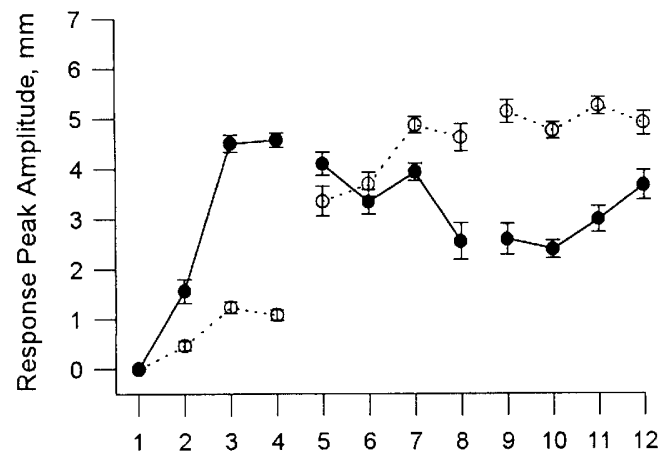

PM Cannula, T1 \& T2

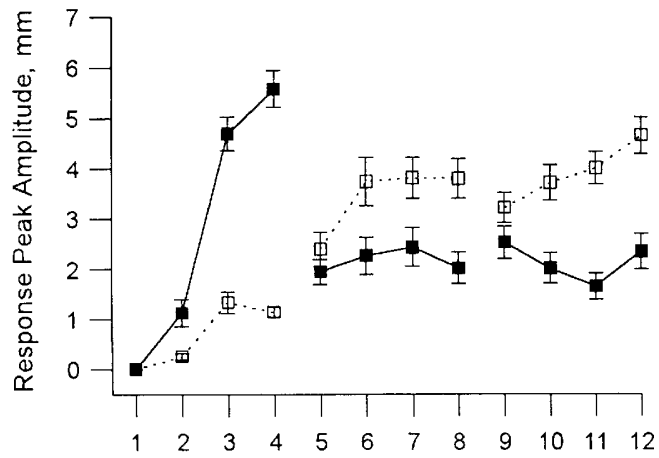

IP Cannula, T1 \& T2

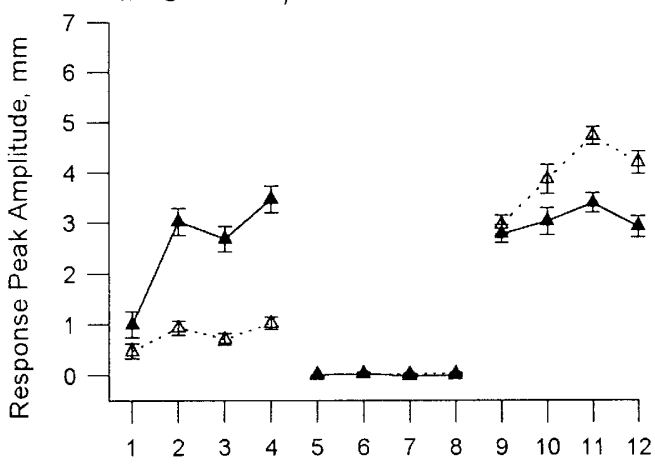

All Groups, T1-T2

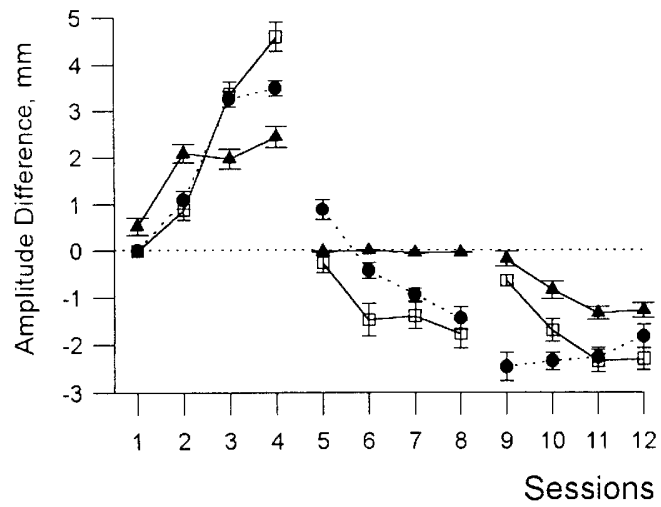

Control, T1 \& T2, 10 Unpaired

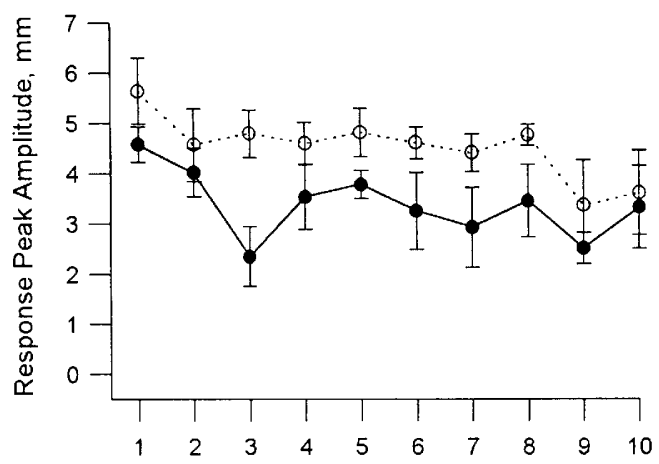

PM Cannula, T1 \& T2, 10 Unpaired

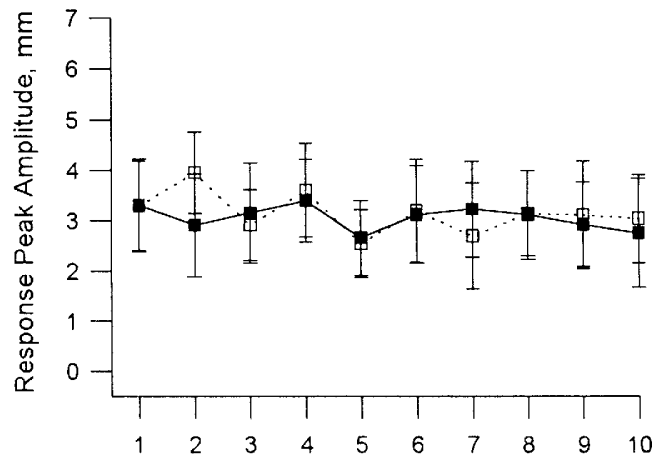

IP Cannula, T1 \& T2, 10 Unpaired

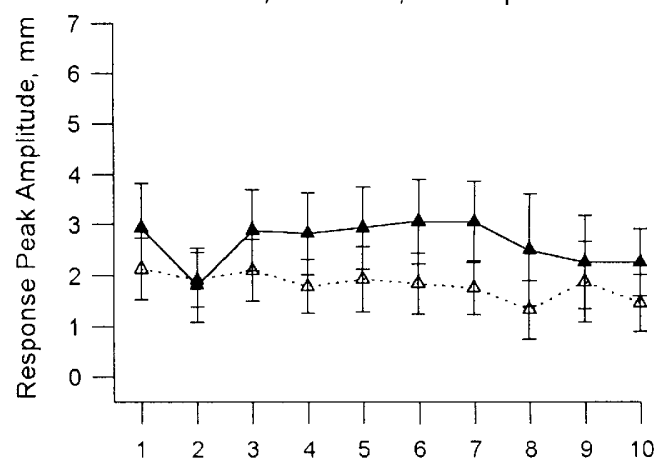

All Groups, T1-T2, 10 Unpaired

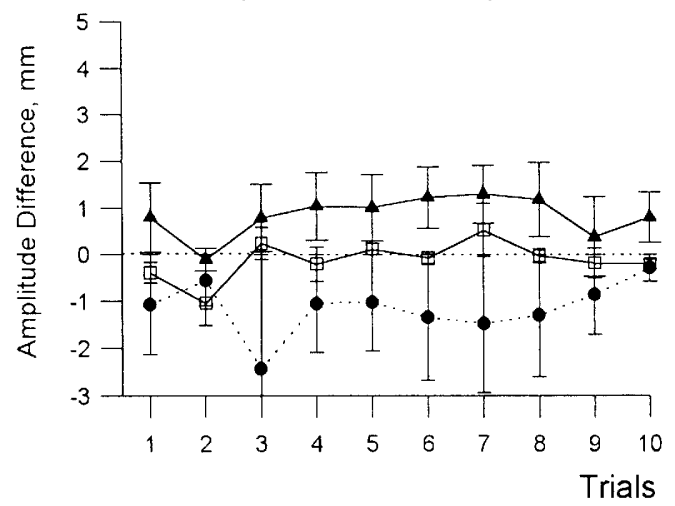

Figure 4: Experiment 1 group mean response peak amplitudes within the T1 and T2 time windows on conditioning sessions (left) and on the 10-unpaired session (right). T1 and T2 plot symbols: group C, T1 (O), T2 (O); group PM, T1 ( $\mathbf{\square})$, T2 $(\square)$; group IP, T1 $(\mathbf{\Delta})$, T2 $(\triangle)$. T1 - T2 plot symbols: group C $(\bullet)$; group PM $(\square)$; group IP $(\boldsymbol{\Delta})$. 
Yeo et al.

Figure 5: Signal-averaged NM CR waveforms from the 10-unpaired session for each subject in experiments 1 and 2 . In experiment 1 , for all subjects, all 10 trials are averaged. In experiment 2 , averages are of all 10 trials for subjects in control group $\mathrm{C}$ but are only from trials 1-5 for subjects in the IP cannula group. Five trials were used in these subjects because extinction was quite rapid. The solid line indicates CS onset (CS), and the broken lines indicate the two ISIs of 250 and $650 \mathrm{msec}$.

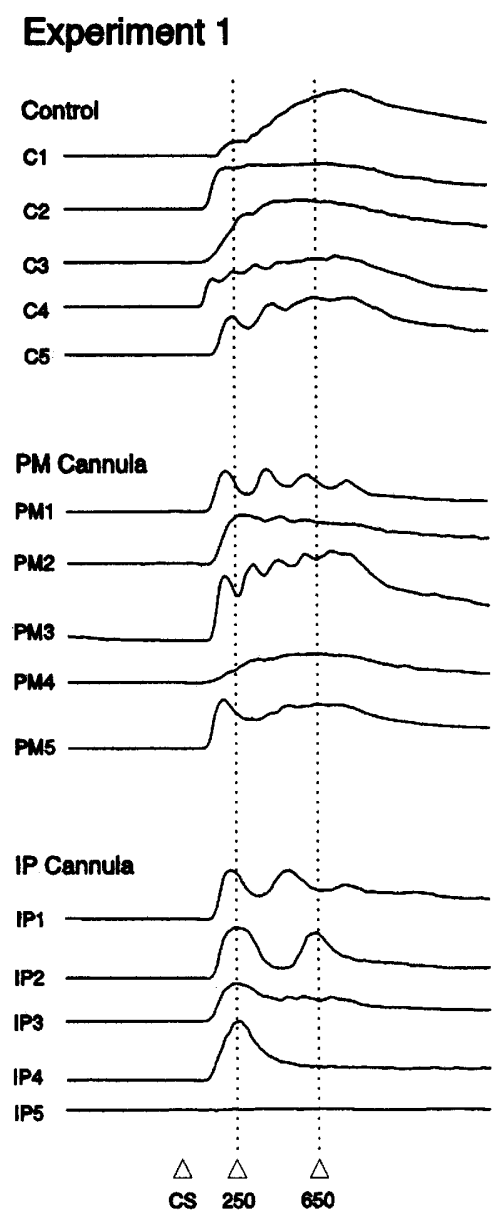

\section{Experiment 2}

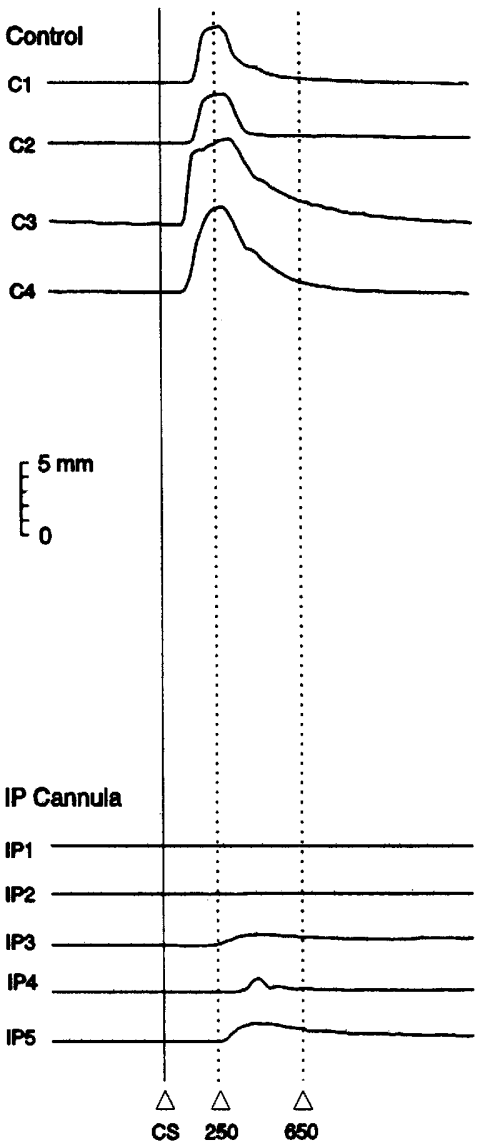

peak. This segmentation was seen most clearly during the 10-unpaired session and was seen on individual trials and not as a simple consequence of the signal-averaging procedure. The frequency of the oscillations varied across subjects.

Overall, group PM showed rather less retention from the stage 2 conditioning than the group $\mathrm{C}$ controls-T1 and $\mathrm{T} 2$ amplitudes were similar throughout the 10 trials. But, Figure 5 reveals that all subjects in group PM had developed longer latency response components. Subjects PM1-PM3 displayed some segmentation of their responses as had some group $\mathrm{C}$ subjects.

Group IP showed responses consistent with very low levels of acquisition in stage 2 . Figure 5 reveals that subjects IP1-IP3 retained a distinct short-latency component of $\sim 250 \mathrm{msec}$, and they acquired a smaller, long-latency component with $\sim 650$ msec. Subject IP4 had only the short-latency component and no evidence of longer latency component at all. IP5 had no overt NMRs in this session but quickly developed CRs in session 9. T1 amplitudes were consistently greater than T2 amplitudes throughout the session, though T2 amplitudes were greater than they had been in stage 1 (Fig. 5).

The T1 - T2 plots reveal the low levels of stage 2 learning in group IP, intermediate levels in group PM, and high levels in group C. One-way ANOVA revealed that the groups were significantly different $[F(2,13)=4.66, P<0.05]$. Student-NewmanKeuls multiple comparison tests revealed that groups $\mathrm{C}$ and IP were significantly different $(r=3$, $q=4.32, P<0.05$ ), but groups $\mathrm{C}$ and $\mathrm{PM}$ were not $(r=2, q=2.31, P>0.05)$.

STAGE 3

Conditioning with the 650-msec ISI in control group $\mathrm{C}$ did not significantly improve on the learning evident in session 8; T1 and T2 amplitudes both increased slightly. T1 - T2 measures showed performance remained relatively stable through stage

$$
\begin{array}{llllllllllllllllll}
\hline & E & A & R & N & I & N & G & \mathbf{Q} & M & E & M & O & R & Y
\end{array}
$$


3. PM group subjects began stage 3 with a poorer dissociation between $\mathrm{T} 1$ and $\mathrm{T} 2$ amplitudes than had been given at the end of stage 2 . But, T2 amplitudes developed quickly, so that by session 11 , performance was equivalent to group $\mathrm{C}$ controls. T1 - T2 plots confirm that learning by PM group subjects was not fully retained in stage 3 , but relearning was quite rapid to give performance similar to controls by session 11. Group IP subjects began stage 3 with similar T1 and T2 amplitudes that dissociated progressively over the four sessions but that did not approach the levels obtained in PM and $\mathrm{C}$ groups. Figure 3 reveals that in subject IP2, conditioned responses modified during stage 3 in much the same way as did CRs of subject C1 during stage 2 .

Two-way repeated measures ANOVA on T1 T2 values through sessions 9-12 revealed that the groups were significantly different $[F(2,13)=9.02$, $P<0.05$ ]; Student-Newman-Keuls post hoc tests revealed that groups $\mathrm{C}$ and IP were significantly different ( $r=3, q=5.93, P<0.05$ ) but groups $\mathrm{C}$ and PM were not $(r=2, q=2.30, P>0.05)$.

Two-way repeated-measures ANOVA on T1 - T2 values for sessions 5-8 of group $C$ and sessions 9-12 of group IP revealed that, though there was a slight trend toward more rapid acquisition by group IP consistent with some learning by this group in the inactivation sessions 5-8, this difference was not significant $[F(1,8)=1.016$, $P>0.05]$.

\section{SUMMARY}

Subjects IP1-IP 4 had good retention of CRs in the 10-unpaired session. The responses had strong peaks with $\sim 250 \mathrm{msec}$ of latency consistent with those that had developed in stage 1 . In three cases (subjects IP1-IP3) there were low-amplitude components with $\sim 650 \mathrm{msec}$ of latency. These longer latency responses had not been present in stage 1 , and their topographies were equivalent to those produced by conditioning with an ISI of $650 \mathrm{msec}$, strongly supporting the suggestion that these responses had been learned during the muscimol inactivation. But, the $\mathrm{T} 1-\mathrm{T} 2$ amplitude analysis of the 10-unpaired session revealed that $650-\mathrm{msec}$ response levels were significantly lower than those in control group C. The amplitudes of $650-\mathrm{msec}$ peak responses in subjects IP1-IP3 were similar to those seen in the first session of stage 2 in control group C subjects; so four sessions of conditioning during nuclear inactivation resulted in a perfor- mance no greater than that obtained in a single session under control conditions. The one subject (IP5) of the IP group that showed little evidence of any retention from either stage 1 or stage 2 during the 10-unpaired session rapidly produced CRs after a few presentations of the US in stage 3, suggesting that the muscimol infusions had not produced general, long-term impairments in the ability to express CRs. The levels of acquisition during stage 2 for group IP were very low because they did not significantly enhance subsequent acquisition in stage 3 .

\section{ESTIMATION OF SPREAD OF MUSCIMOL}

Figure 6 shows the percentage CRs, on unpaired trials, for all subjects in the IP and PM groups plotted against the distance of the cannula tip from our estimated location of the rostral anterior interpositus nucleus (see Materials and Methods). Muscimol injections up to $4 \mathrm{~mm}$ from the target area affect CR frequencies.

\section{Experiment 2}

\section{Materials and Methods}

Experiment 2 was very similar to experiment 1

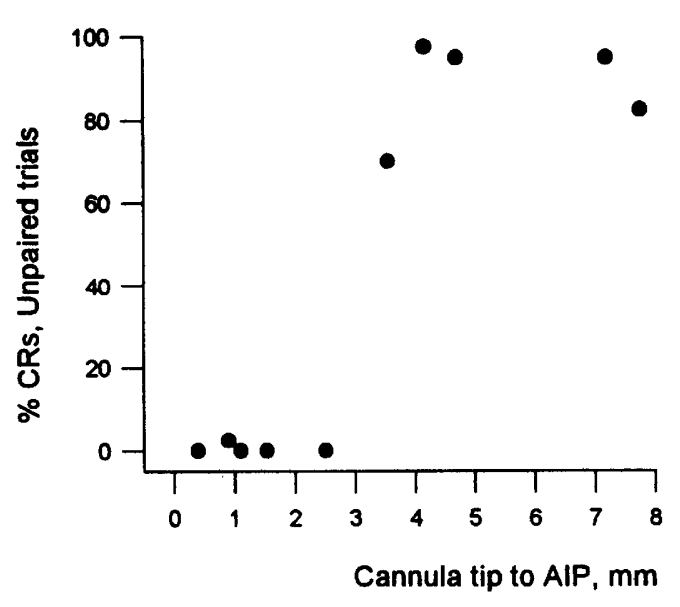

Figure 6: Estimated spread of muscimol. Percent CRs, on unpaired trials in sessions 5-8, for all subjects in the IP and PM groups are plotted against the distance of the cannula tip from the estimated location of the rostral anterior interpositus nucleus. Muscimol infusions up to $3 \mathrm{~mm}$ from the nucleus completely abolish all CRs. Infusions of $\sim 4 \mathrm{~mm}$ or more from the rostral interpositus only slightly impair CR frequency.

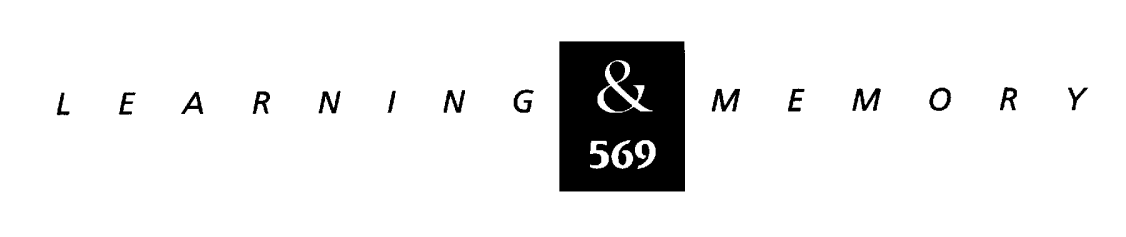


Yeo et al.

except that initial training in stage 1 was with a 650-msec ISI and subsequent training in stages 2 and 3 were with a 250-msec ISI. This protocol was designed to counterbalance any differential effects of muscimol on long- and short-latency response learning. There were two groups of subjects: control group $\mathrm{C}$ and interpositus nucleus-cannulated group IP.

\section{SUBJECTS}

The subjects were 20 male, Dutch belted rabbits weighing between $1.7 \mathrm{~kg}$ and $2.4 \mathrm{~kg}$. They were individually housed with free access to food and water and maintained on a 12-hr light-dark cycle.

\section{EXPERIMENTAL PROTOCOLS}

(1) EXPERIMENTAL DESIGN

There were two experimental groups (see Table 3). Group C subjects were normal controls, and group IP subjects had an infusion cannula implanted close to the interpositus nucleus of the cerebellum. The experiment was in three stages. In stage 1, all subjects received four, daily sessions of delay NMR conditioning with an ISI of $650 \mathrm{msec}$ (sessions 1-4). On the following day all subjects began stage 2 , which consisted of four, daily conditioning sessions (sessions 5-8) with an ISI of 250 msec. Subjects of groups 2 and 3 received muscimol infusions before each conditioning session. In all cases, each daily infusion dose was 7.7 nmoles ( $1 \mu \mathrm{l}$ of $7.7-\mathrm{mmole}$ muscimol hydromide). All subjects were then rested for 3 days. On the next day, in stage 3, all subjects received 10 unpaired presentations of the CS alone (10-unpaired session), and they then started four, daily conditioning sessions with an ISI of $250 \mathrm{msec}$ (sessions 9-12). All other details were as in experiment 1.

\section{(2) NMR CONDITIONING PROCEDURE}

All details were as in experiment 1 except that during stage 2 , a single infusion of $11.55 \mathrm{~nm}$ muscimol ( $1.5 \mu \mathrm{l}$ of 7.7 -mmole solution) was given to each subject in the IP group $1 \mathrm{hr}$ before each conditioning session.

DATA ANALYSIS, SURGERY, MUSCIMOL INFUSION, AND HISTOLOGY

All procedures were as in experiment 1.

\section{Results}

\section{VERIFICATION OF CANNULA PLACEMENTS AND GROUP ASSIGNMENT}

There were four subjects in control group C. Eight subjects were implanted with a cannula directed at the interpositus nucleus. Of these, two gave CRs erratically during stage 2 and were deemed to have had faulty infusions of muscimol on one or more sessions and one subject did not learn during stage 1 . Five subjects satisfied our criteria for inclusion in the IP group, and the locations of their cannula tips are shown in Figure 2. All are close to the anterior interpositus nucleus.

ACQUISITION OF SHORT- AND LONG-LATENCY CRS

STAGE 1

All subjects in both groups acquired CRs during stage 1 training with a 650 -msec ISI. Signal-

Table 3: Experiment 2-experimental design

\begin{tabular}{|c|c|c|c|c|c|}
\hline \multirow[b]{2}{*}{ Experiment 2} & \multirow{2}{*}{$\frac{\text { Stage 1 }}{\text { sessions } 1-4}$} & \multirow{2}{*}{$\frac{\text { Stage } 2}{\text { sessions 5-8 }}$} & \multirow{2}{*}{$\begin{array}{l}\text { interval } \\
3 \text { days }\end{array}$} & \multicolumn{2}{|c|}{ Stage 3} \\
\hline & & & & 10 unpaired & sessions $9-12$ \\
\hline Group C & conditioning & conditioning & & $10 \mathrm{CS}$ & conditioning \\
\hline $\begin{array}{l}\text { Nonoperated control } \\
(n=4)\end{array}$ & ISI $650 \mathrm{msec}$ & ISI $250 \mathrm{msec}$ & & $310 \mathrm{msec}$ & ISI $250 \mathrm{msec}$ \\
\hline Group IP & conditioning & conditioning & & $10 \mathrm{CS}$ & conditioning \\
\hline $\begin{array}{l}\text { Interpositus nucleus cannula } \\
(n=6)\end{array}$ & ISI $650 \mathrm{msec}$ & $\begin{array}{c}\text { ISI } 250 \text { msec } \\
\text { Muscimol } \\
(7.7 \text { nmole })\end{array}$ & & $310 \mathrm{msec}$ & ISI $250 \mathrm{msec}$ \\
\hline
\end{tabular}

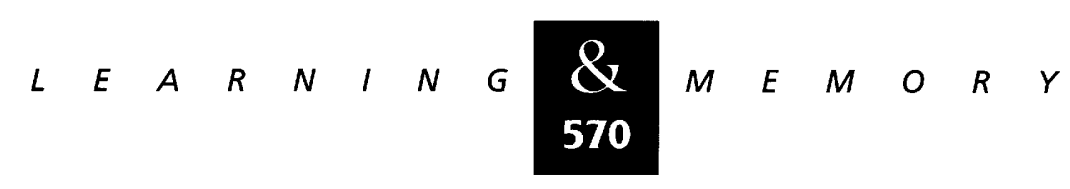


Control, T1 \& T2
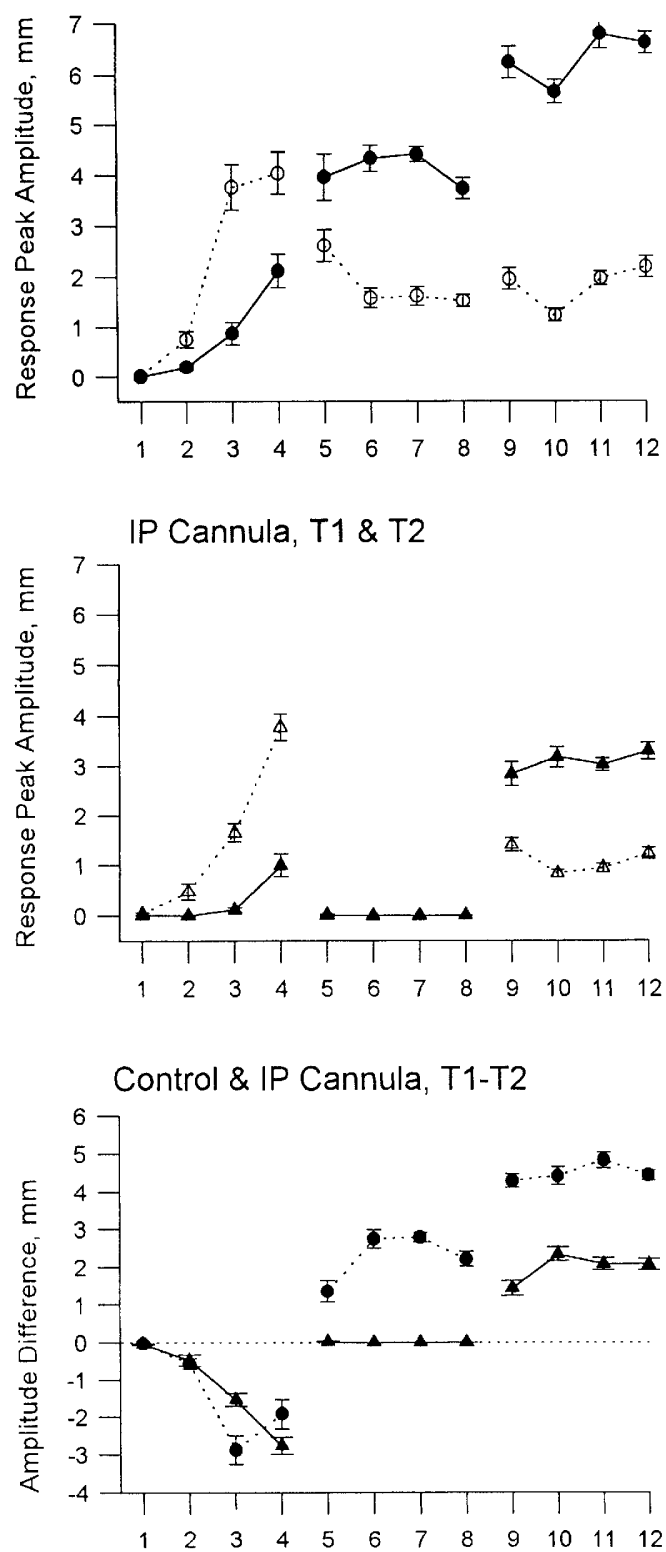

Control, T1 \& T2, 10 Unpaired

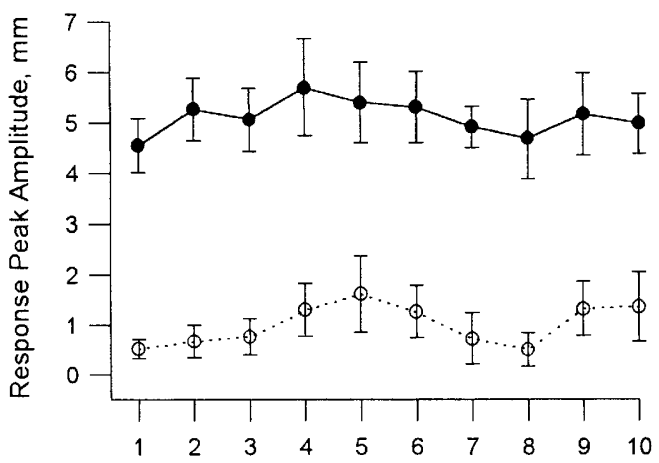

IP Cannula, T1 \& T2, 10 Unpaired
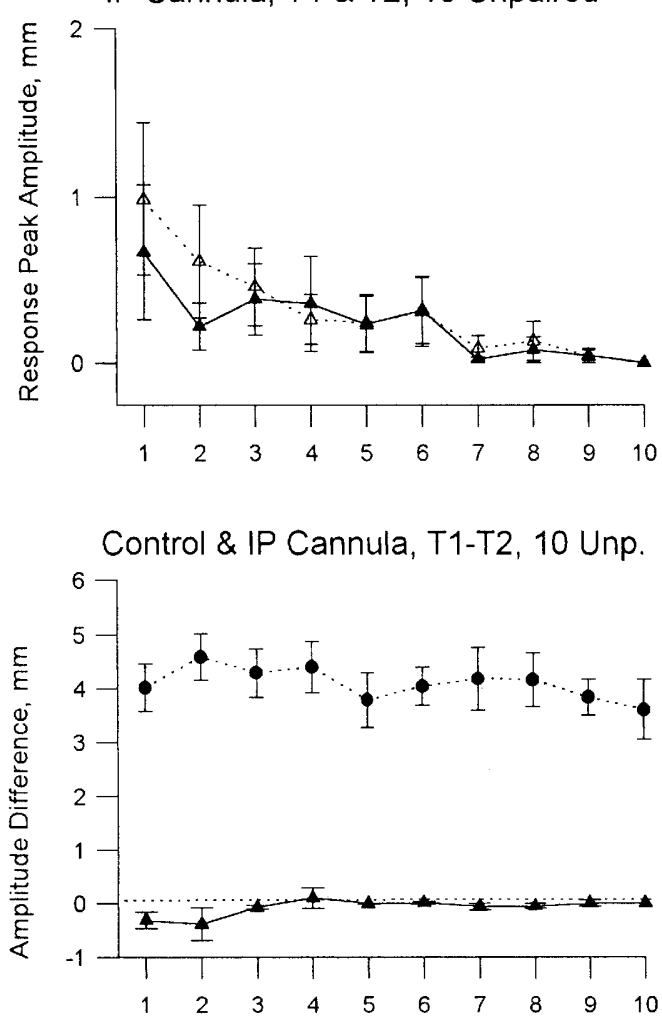

Trials

Figure 7: Experiment 2 group mean response peak amplitudes within the T1 and T2 time windows on conditioning sessions (left) and on the 10-unpaired session (right). All conventions are as in Fig. 4.

averaged response waveforms of a representative example from groups $\mathrm{C}$ and IP are shown in Figure 4. CRs developed with a latency-to-peak of $\sim 680$ msec.

Group mean T1 and T2 analysis revealed that groups $\mathrm{C}$ and $\mathrm{PM}$ developed CRs with T2 amplitudes of $\sim 4 \mathrm{~mm}$ by session 4 (see Fig. 7). In both groups, T2 amplitudes were clearly greater than T1 amplitudes. Two-way repeated-measures ANOVA of the T1 - T2 measure on sessions $1-4$ confirmed that learning in stage 1 was not significantly different in groups $\mathrm{C}$ and $\mathrm{IP}[F(1,7)=0.386, P>0.05]$.

It should be noted that overall, for both groups, CRs with latency-to-peak of $\sim 650 \mathrm{msec}$ did not develop with such large amplitudes as those of $\sim 250 \mathrm{msec}$ in experiment 1 . In terms of CR amplitude, conditioning was less developed than that in experiment 1 .

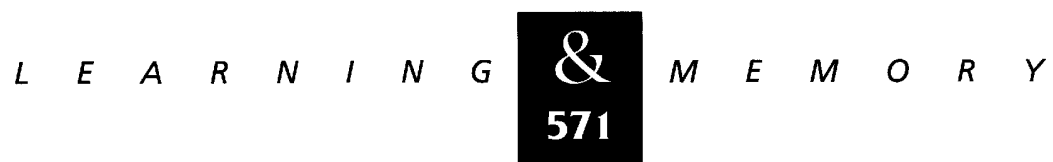


Yeo et al.

STAGE 2

In group $\mathrm{C}$ subjects, conditioning with an ISI of $250 \mathrm{msec}$ rapidly resulted in enhanced $\mathrm{T} 1 \mathrm{am}$ plitudes and decreased T2 amplitudes. Reversal of $\mathrm{T} 1$ and $\mathrm{T} 2$ amplitudes was substantially complete by session 6 of stage 2 .

Group IP subjects were selected for full inactivation during stage 2 , and so their T1 and T2 amplitudes were at baseline levels.

10-UNPAIRED SESSION

As in experiment 1, 10 unpaired presentations of the $\mathrm{CS}$ revealed $\mathrm{CR}$ topographies before commencing conditioning in stage 3 . Control group $\mathrm{C}$ showed very good retention from session 8 , with all $\mathrm{T} 1$ amplitudes much greater than $\mathrm{T} 2$ amplitudes. In the IP group, subjects IP1 and IP2 had responses at baseline response amplitudes and subjects IP3-IP5 had responses that were initially low and then extinguished progressively during the 10unpaired session. Because the responses extinguished, the signal-averaged responses shown in Figure 5 were obtained from the first five trials only. In subjects IP3-IP5, the responses were clearly of long duration, with no evidence of onsets before $250 \mathrm{msec}$. Because absolute amplitudes were low, T1 - T2 plots reveal that responses in the two time domains were very similar. Comparing the first trial of the 10-unpaired session with session 4 , there had been a large decline in $\mathrm{T} 2$ amplitudes, whereas $\mathrm{T} 1$ amplitudes were maintained.

One-way ANOVA confirmed that the difference between the T1 - T2 measure of groups C and IP was significant $[F(1,7)=205.0, P<0.05]$.

STAGE 3

Further conditioning with the 250-msec ISI in control group $C$ continued to develop T1 amplitudes. T1 - T2 measures showed that performance increased sharply in stage 3. Group IP reversed the distribution of $\mathrm{T} 1$ and $\mathrm{T} 2$ amplitudes seen in session 4 within a single session. A two-way, repeatedmeasures ANOVA on T1 - T2 measures throughout stage 3 revealed that groups $C$ and IP were significantly different $[F(1,7)=24.98, P<0.05]$. T1 - T2 plots reveal that performance by the IP group was very similar in stage 3 to the performance of control group $\mathrm{C}$ in stage 2 ; a two-way, repeated-measures ANOVA confirms that there were no significant differences $[F(1,7)=0.43$, $P>0.05]$.

\section{SUMMARY}

Overall, the development of long-latency CRs with conditioning at a $650-\mathrm{msec}$ ISI in stage 1 was poorer than the development of short-latency CRs with conditioning at $250 \mathrm{msec}$ in stage 1 of experiment 1 , consistent with other findings (Kehoe and Napier 1991). In control group C, suppression of these long-latency responses and the development short-latency responses in stage 2 were correspondingly rapid. For the IP group, the weak responses seen in the 10-unpaired session might relate to a general impairment produced by muscimol infusion, but this is unlikely as paired trials in stage 3 rapidly instated CRs. The low response levels appear to relate to the small response amplitudes that were obtained in stage 1 . The similarity of the small $\mathrm{T} 1$ and $\mathrm{T} 2$ responses in this session may be consistent with a low level of learning during muscimol inactivation but the averaged response waveforms indicate little or no enhancement of responsivity around $250 \mathrm{msec}$. Any learning that might have occurred under muscimol was slight, as group IP learning in stage 3 was very similar to control group C learning in stage 2 .

\section{General Discussion}

Experiments 1 and 2 clearly demonstrated that unilateral infusions of muscimol into the cerebellar nuclei greatly impaired but did not, in all cases, completely prevent acquisition of newly timed CRs. These findings are evidence that the ipsilateral cerebellum is essential for the normal acquisition of conditioning but that some learning is mediated by different circuitry.

\section{EXTENTS OF MUSCIMOL INACTIVATION}

To test accurately cerebellar involvement in NMR conditioning, inactivation of the critical areas had to be complete. We used smaller doses of muscimol than some that have been used recently. The 7.7-nmole and 11.55-nmole infusions we used are equivalent to $51 \%$ and $77 \%$ of the doses used by Krupa et al. (1993) in their recent study of acquisition, but our doses were fully sufficient to pre-

$$
\text { n...... 睓" n... }
$$


vent all expression of CRs acquired in stage 1 of the experiments during conditioning in stage 2 . It should be noted that, in all sessions, every tenth presentation of the CS was unpaired with the US. These unpaired CS trials allowed for CRs to be tested at latencies up to $1000 \mathrm{msec}$ after CS onset. For all cases admitted to the IP groups, CRs were absent throughout this time period. In contrast, Welsh and Harvey (1991) did not assess the efficacy of their lidocaine injections with unpaired CS presentations; so delayed CRs after US presentation would not have been detected. Welsh and Harvey (1989) themselves had found that some lesions of the cerebellar nuclei can lead to a depression of CR amplitude and extension of their latency into the post-US period, and so they advocated the use of unpaired CS presentations fully to assess cerebellar contributions to conditioning. In their own inactivation study, exclusive use of paired, CS-US trials to test the efficacy of lidocaine inactivation would not have ruled out subjects with incomplete inactivation of the interpositus nucleus.

Krupa et al. (1993) used autoradiography to determine the spread of a 15-nmole dose of tritiated muscimol-equivalent to the dose used to inactivate the cerebellar nuclei during acquisition. After $90 \mathrm{~min}$, when subjects would have been halfway through a normal conditioning session, there was spread of muscimol through the cerebellar nuclei and into the overlying cerebellar cortex, especially in lobule HVI. In our study we estimated the spread of our lower muscimol doses with a behavioral measure. Muscimol infusions in the paramedian lobe more than $\sim 4 \mathrm{~mm}$ from the anterior interpositus nucleus did not impair CRs. Assuming a similar uptake and distance for spread of the drug from infusions in the nuclei, areas of cerebellar cortex in lobule HVI, ansiform lobe, and anterior lobe would also have been affected in the present study.

As we suggested previously (Hardiman et al. 1996), cerebellar cortical function is unlikely to be normal even if muscimol infusions were completely restricted to the cerebellar nuclei. Loss of nucleo-olivary inhibition and disruption of nucleocortical inputs would disturb function in an entire olivocorticonuclear compartment. So, inactivation of the cerebellar nuclei during NMR conditioning would not exclusively test for their involvement in acquisition and impairment of acquisition indicates that either the cerebellar cortex or the nuclei, or both are actively involved in the learning. For these reasons, in this experiment, we made no particular attempt to restrict muscimol infusions to the cerebellar nuclei, and our procedures should be viewed as general inactivations of the ipsilateral cerebellum.

\section{INACTIVATION OF THE CEREBELLAR NUCLEI GREATLY IMPAIRS ACQUISITION OF A NEW-LATENCY CR}

In both experiments, cerebellar inactivations substantially prevented the acquisition of a newlatency $\mathrm{CR}$, as assessed by performance in the 10unpaired session and during sessions 9-12. Although some subjects in group IP had low levels of responses in the 10-unpaired session, all very rapidly developed responses within a few trials in stage 3 consistent with the suggestion that the muscimol inactivations had not led to any longterm deficits in cerebellar function. In those cases in which small, new-latency responses had developed during the four conditioning sessions with nuclear inactivation, they were consistent with those that occurred within a single session or less in the control group $\mathrm{C}$ subjects. The major effect of the nuclear inactivation was a significant impairment in acquisition of a new-latency response. Because muscimol impaired the development of new responses in experiments 1 and 2, there is no evidence to suggest that it differentially affects shortlatency and long-latency responses.

The nonappearance of CRs after training with cerebellar inactivation has generally been assumed to implicate the cerebellum directly in the acquisition process (Clark et al. 1992; Krupa et al. 1993; Thompson and Krupa 1994). There are other interpretations. Any learning that does occur might be state-dependent, that is, may be exhibited only under conditions similar to those present when the memory was formed. Such conditions could include drug-induced changes in the excitatory properties of the CS itself (Harvey 1987). Because, in cerebellar nuclear inactivation experiments, the conditions under which memories might be formed are explicitly those under which there can be no expression of the CRs, state-dependent learning (SDL) effects are very difficult to test.

Local infusions of drugs could produce statedependent effects in two different ways. First, the drug could affect sensory processing in the target area and its related circuitry directly, but this possibility does not change our analysis of what circuitry is essential for normal conditioning (Ramnani and Yeo 1996). Whether normal plasticity is

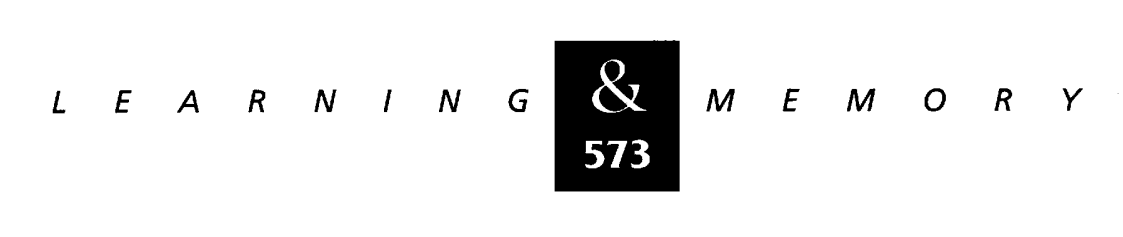


Yeo et al.

impaired or state-dependent plasticity is induced in the target circuitry, both are consistent with the essential involvement of that circuitry in the conditioning process.

Second, the drug may diffuse into areas outside the target or it may be picked up by the circulation to affect sensory processing in other brain areas. Group PM in experiment 1 was designed to control for such effects. In this group, learning proceeded relatively normally during stage 2 with muscimol infusions into noncritical areas of the paramedian lobe. However, when trained again without muscimol in stage 3, the performance was clearly poorer than it had been in the last session of stage 2 though it improved with further training, and overall performance was not significantly different from control subjects in this stage. The inability of subjects in this group to maintain fully CR levels obtained in the drug condition of stage 2 into the no-drug condition of stage 3 must be taken as evidence for small but not significant SDL effects. We suggest that state-dependent effects of muscimol infusion cannot be ruled out entirely in all experiments to date, and the apparently complete prevention of acquisition seen in several de novo acquisition experiments should be viewed with caution.

In experiments to date, most consideration has been given to assessing the spread of the inactivating agent and its efficacy in inactivating essential circuitry during the acquisition period itself. This restricted view of the duration of muscimol effects is not justified. In all types of learning there is a critical period following acquisition during which memories are consolidated (for review, see McGaugh 1996). Interference with this consolidation process, especially with drugs that affect protein synthesis (for review, see Davies and Squire 1984), can lead to a failure of long-term storage of memory despite evidence for short-term improvements during the learning session itself.

In some cases the muscimol infusions produced small changes in head and neck posture that persisted after the end of the training sessions, indicating that they continued to exert effects for $>2$ $\mathrm{hr}$. The drug could, therefore, impair learning by interfering with consolidation rather than with acquisition, whether there were overt signs of persistent drug effects or not. If the drug continues to spread during these extended periods, then it may invade additional areas, including ones outside the cerebellum, that might be involved in consolidation. An apparent failure to acquire during musci- mol inactivation of the cerebellum might really be produced by interfering with consolidation in areas outside the cerebellum. This rather gloomy analysis of the use of muscimol for testing cerebellar involvement in the acquisition of NMR conditioning is brightened, however, by considering the behavior of group PM subjects in stage 2 . These subjects clearly produced day-by-day improvements in their new response learning that would not have been possible had consolidation been disrupted. However, it must be recognized that the locations of control muscimol injections are, inevitably, different from those of the IP group; so spread into other areas can never be matched entirely. Further work is necessary to resolve whether state-dependent or consolidation effects should significantly modify the parsimonious interpretation that inactivating the cerebellum impairs acquisition of NMR conditioning.

\section{LOW LEVELS OF ACQUISITION MEDIATED \\ BY CIRCUITRY OUTSIDE THE \\ IPSILATERAL CEREBELLUM}

Whatever the exact nature of the significant impairment of learning during unilateral cerebellar inactivation, it is clear that the ISI-shift experimental design is a very sensitive one and that very low levels of small amplitude, new-latency responses did develop in some subjects in experiment 1 . There can be no doubt that these responses developed as a consequence of conditioning in stage 2, because their timing was appropriate to the ISIs used. But, it is clear that the levels of learning possible under the muscimol inactivation must have been very low, because they did not significantly enhance subsequent acquisition during reinforced trials with the second ISI. Comparison of acquisition rates during stage 2 for control subjects with rates during stage 3 for inactivated subjects revealed that the slight trend toward more rapid conditioning in the inactivated subjects was not significant.

Using a cross-modal, three-stage experimental design similar to that of Welsh and Harvey (1991), but instead using muscimol to inactivate the cerebellar nuclei, B.D. Cipriano, D.J. Krupa, W. Almanza, and R.F. Thompson (unpubl.) found no new responses to the tone CS with unreinforced presentations of the tone after the inactivation, suggesting that cerebellar inactivations with lidocaine were probably incomplete in the Welsh and Harvey study.

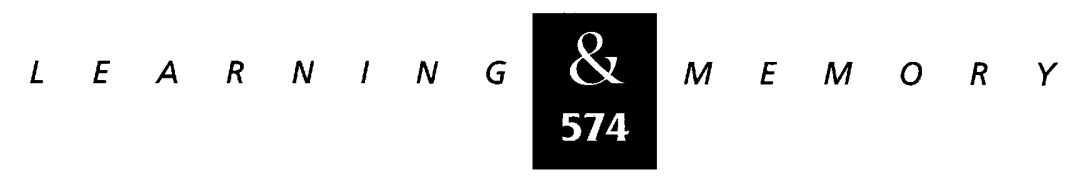


In the present study the muscimol inactivations were obviously complete. Without the need to shift the test CS modality, there were no measurable responses at all, including during unpaired CS presentations; so the low levels of learning to the new ISI must have been mediated by circuitry outside the inactivation. There have been many proposals that NMR conditioning is supported, entirely or partially, by circuitry outside the cerebellum (Welsh and Harvey 1989, 1991; Kelly et al. 1990; Bracha et al. 1994; Llinas and Welsh 1993) but few suggestions for alternative neural substrates. Bracha et al. (1991) disrupted CRs with lidocaine infusions in the spinal trigeminal nucleus and suggested that essential plasticity could be there. Some infusions impaired CR amplitudes and enhanced UR amplitudes in just the same way as do lesions of the cerebellar cortex. Other infusions impaired CR and UR amplitudes in the same way as do lesions of the cerebellar nuclei. The same reservations that have been applied to interpretations of cerebellar lesions or inactivations must be applied to these trigeminal inactivations. These brainstem areas may be important for the regulation of conditioned movements rather than for learning.

In a recent lesion study, we have found that conditioned NMRs (Gruart and Yeo 1995) are, to a small extent, dependent on the contralateral cerebellar cortex, a finding consistent with physiological evidence for some contralateral cerebellar cortical control of eyeblink in ferrets (Ivarsson and Hesslow 1993). If there is some neural plasticity for NMR conditioning within or mediated by the contralateral cerebellum, then the ipsilateral inactivation used in this and in other inactivation studies would not have prevented it. In the case of de novo conditioning in a two-stage design, we suggest that the very low levels of learning that might be mediated by the contralateral side would be difficult to assess as acquisition would only be slightly more rapid in the second stage. In most previous two-stage studies, inactivated subjects subsequently learn at the same rate as naive controls (Clark et al. 1992; Krupa et al. 1993; Nordholm et al. 1993). In a recent study with experience-matched controls, we could not rule out the possibility of low levels of learning under muscimol inactivation of the cerebellar nuclei (Hardiman et al. 1996). If, as seems likely, conditioning to a new modality $C S$ is supported by neural mechanisms similar or related to those mediating conditioning to a new ISI, then, in the three-stage design of Welsh and Harvey (1991), the apparently high levels of learning during inactivation in stage 2 may, instead, have been quite weak. Because the ISIs in stages 1 and 2 of their experiment were identical, conditioning that developed in stages 1 and 2 cannot be dissociated. If there were low levels of conditioning during stage 2 , general transfer would ensure high levels of acquisition. In contrast, the current, three-stage design experiment allows a clear dissociation between conditioning that developed in stages 1 and 2 and reveals that levels of learning in stage 2 were very low, but they may be adequate to support transfer of learning in a three-stage design with identical ISIs.

\section{CONCLUSION}

Our data are consistent with the suggestion that the ipsilateral cerebellum plays a major role in the acquisition of NMR conditioning, and lesion studies have indicated that there is a weak contribution to CRs from the contralateral side. A more complete analysis of the role of the cerebellum in NMR conditioning will require bilateral inactivations. Unilateral, local inactivation of the inferior olive with lidocaine inactivates climbing fibers to the cerebellum bilaterally because decussating efferent fibers pass close to corresponding areas in the contralateral olive. It is significant that J.P. Welsh and J.A. Harvey (unpubl.), using a threestage experimental design identical to that in their cerebellar nuclear inactivation study, prevented acquisition completely to the tone CS with lidocaine inactivations of the inferior olive that were, inevitably, bilateral in their action.

This analysis of the laterality of cerebellar contributions to NMR conditioning reconciles apparently disparate findings from several laboratories and confirms an essential role for the cerebellum in learning a simple motor response. In a recent review, de Schutter and Maex (1996) consider evidence from studies of eye-blink conditioning in gene-knockout mice, and they argue that this and other forms of motor learning do not have an essential cerebellar component. We suggest that careful analysis of the evidence from studies of cerebellar inactivations during acquisition and extinction of NMR conditioning learning should lead to a quite different conclusion.

\section{Acknowledgments}

We thank Mervyn Hardiman for pilot studies of muscimol effects and assistance with the guide cannula

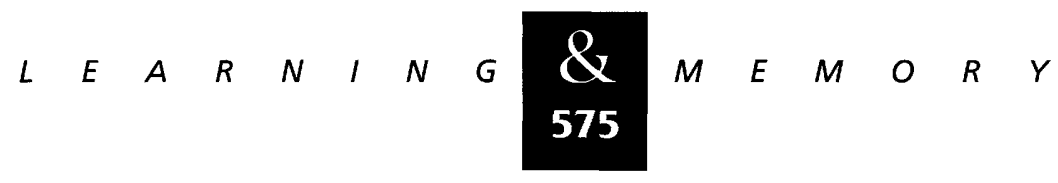


Yeo et al.

position reconstructions. This work was supported by Medical Research Council grant G9100635.

\section{References}

Albus, J.S. 1971. A theory of cerebellar function. Math. Biosci. 10: 25-61.

Bloedel, J.R. and V. Bracha. 1995. On the cerebellum, cutaneomuscular reflexes, movement control and the elusive engrams of memory. Behav. Brain Res. 68: 1-44.

Bracha, V., J.-Z. Wu, S. Cartwright, and J.R. Bloedel. 1991. Selective involvement of the spinal trigeminal nucleus in the conditioned nictitating membrane reflex of the rabbit. Brain Res. 556: 317-320.

Bracha, V., M. Webster, N.K. Winters, K.B. Irwin, and J.R. Bloedel. 1994. Effects of muscimol inactivation of the cerebellar interposed-dentate nuclear complex on the performance of the nictitating membrane response in the rabbit. Exp. Brain Res. 100: 453-468.

Clark, R.E., A.A. Zhang, and D.G. Lavond. 1992. Reversible lesions of the cerebellar interpositus nucleus during acquisition and retention of a classically conditioned behavior. Behav. Neurosci. 106: 879-888.

Davies, H.P. and L.R. Squire. 1984. Protein synthesis and memory: A review. Psychol. Bull. 96: 518-559.

De Schutter, E. and R. Maex. 1996. The cerebellum: Cortical processing and theory. Curr. Opin. Neurobiol. 6: 759-764.

Gilbert, P.F.C. 1974. A theory of memory that explains the function and structure of the cerebellum. Brain Res. 70: 1-18.

1975. How the cerebellum could memorise movements. Nature 254: 688-689.

Gormezano, I. and C.M. Gibbs. 1988. Transduction of the rabbit's nictitating membrane response. Behav. Res. Methods Instrum. \& Comput. 20: 18-21.

Gormezano, I., N. Schneiderman, E. Deaux, and I. Fuentes. 1962. Nictitating membrane: Classical conditioning and extinction in the albino rabbit. Science 138: 93-106.

Gruart, A. and C.H. Yeo. 1995. Cerebellar cortex and eyeblink conditioning--bilateral regulation of conditioned responses. Exp. Brain Res. 103: 431-448.

Hardiman, M.J., N. Ramnani, and C.H. Yeo. 1996. Reversible inactivations of the cerebellum with muscimol prevent the acquisition and extinction of conditioned nictitating membrane responses in the rabbit. Exp. Brain Res. 110: 235-247.

Harvey, J.A. 1987. Effects of drugs on associative learning. In Psychopharmacology: The third generation of progress (ed. H.Y. Meltzer), pp. 1485-1491. Raven Press, New York, NY.

Hesslow, G. 1994a. Correspondence between climbing fibre input and motor output in eyeblink-related areas in cat cerebellar cortex. J. Physiol. 476: 229-244.

1994b. Inhibition of classically conditioned eyeblink responses by stimulation of the cerebellar cortex in the decerebrate cat. J. Physiol. 476: 245-256.

Ito, M. 1982. Cerebellar control of the vestibulo-ocular reflex-around the flocculus hypothesis. Annu. Rev. Neurosci. 5: 275-296.

1989. Long term depression. Annu. Rev. Neurosci. 12: $85-102$.

Ivarsson, M. and G. Hesslow. 1993. Bilateral control of the orbicularis oculi muscle by one cerebellar hemisphere in the ferret. NeuroReport 4: 1127-1130.

Kehoe, E.J. and P.E. Holt. 1984. Transfer across CS-US intervals and sensory modalities in classical conditioning in the rabbit. Anim. Learn. Behav. 12: 122-128.

Kehoe, E.J. and R. M. Napier. 1991. Temporal specificity in cross-modal transfer of the rabbit nictitating membrane response. J. Exp. Psychol. 17: 26-35.

Kelly, T.M., C.-C. Zuo, and J.R. Bloedel. 1990. Classical conditioning of the eyeblink reflex in the decerebrate-decerebellate rabbit. Behav. Brain Res. 38: 7-18.

Krupa, D.J. and R.F. Thompson. 1995. Inactivation of the superior cerebellar peduncle blocks expression but not acquisition of the rabbit's classically conditioned eye-blink response. Proc. Natl. Acad. Sci. 92: 5097-5101.

Krupa, D.J., J.K. Thompson, and R.F. Thompson. 1993. Localization of a memory trace in the mammalian brain. Science 260: 989-991.

Llinas, R. and J.P. Welsh. 1993. On the cerebellum and motor learning. Curr. Opin. Neurobiol. 3: 958-965.

Marr, D. 1969. A theory of cerebellar cortex. J. Physiol. 202: $437-470$.

Mauk, M.D. and B.L. Ruiz. 1992. Learning-dependent timing of pavlovian eyelid responses: Differential conditioning using multiple interstimulus intervals. Behav. Neurosci.

106: 666-681.

McGaugh, J.L. 1966. Time dependent processes in memory storage. Science 153: 1351-1358.

Nordholm, A.F., J.K. Thompson, C. Desarkissian, and R.F. Thompson. 1993. Lidocaine infusion in a critical region of cerebellum completely prevents learning of the conditioned eyeblink response. Behav. Neurosci. 107: 882-866.

Ramnani, N. and C.H. Yeo. 1996. Reversible inactivations of the cerebellum prevent the extinction of conditioned nictitating membrane responses in rabbits. J. Physiol. 495: $159-168$

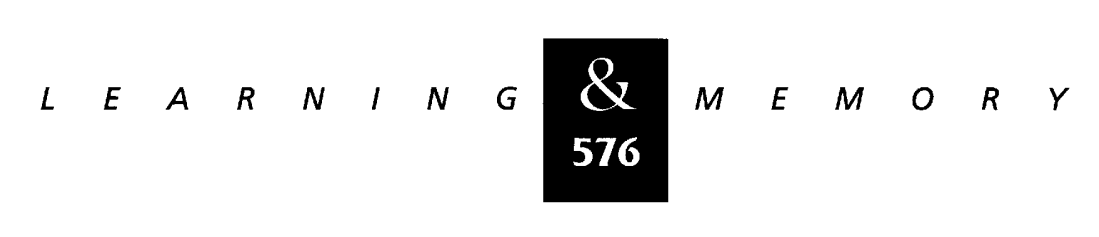


Schreurs, B.G. and E.J. Kehoe. 1987. Cross-modal transfer as a function of initial training level in classical conditioning with the rabbit. Anim. Learn. Behav. 15: 47-54.

Smith, M.C. 1968. CS-US interval and US intensity in classical conditioning of the rabbit's nictitating membrane response. J. Comp. Physiol. Psychol. 66: 679-687.

Thompson, R.F. 1986. The neurobiology of learning and memory. Science 233: 941-947.

Thompson, R.F. and D.J. Krupa. 1994. Organization of memory traces in the mammalian brain. Annu. Rev. Neurosci. 17: 519-549.

Welsh, J.P. and J.A. Harvey. 1989. Cerebellar lesions and the nictitating membrane reflex: Performance deficits of the conditioned and unconditioned response. J. Neurosci. 9: 299-311.

1991. Pavlovian conditioning in the rabbit during inactivation of the interpositus nucleus. J. Physiol. 444: $459-480$.

1992. Role of the cerebellum in voluntary and reflexive movements: History and current status. In The cerebellum revisited (ed. R. Llinas and C. Sotelo), pp. 301-334. Springer-Verlag, New York, NY.

Yeo, C.H. 1987. Cerebellum and classical conditioning. In Cerebellum and neuronal plasticity (ed. M. Glickstein, C.Yeo, and J. Stein), pp. 321-338. Plenum, New York, NY.

1991. Cerebellum and classical conditioning of motor responses. Annu. N.Y. Acad. Sci. 627: 292-304.

Yeo, C.H. and M.J. Hardiman. 1992. Cerebellar cortex and eyeblink conditioning: A reexamination. Exp. Brain Res. 88: $623-638$.

Yeo, C.H., M.J. Hardiman, and M. Glickstein. 1984. Discrete lesions of the cerebellar cortex abolish the classically conditioned nictitating membrane response of the rabbit. Behav. Brain Res. 13: 261-266.

1985a. Classical conditioning of the nictitating membrane response of the rabbit. I. Lesions of the cerebellar nuclei. Exp. Brain. Res. 60: 87-98.

1985b. Classical conditioning of the nictitating membrane response of the rabbit. II. Lesions of the cerebellar cortex. Exp. Brain. Res. 60: 99-113.

1985c. Classical conditioning of the nictitating membrane response of the rabbit. III. Connections of cerebellar lobule. Exp. Brain. Res. 60: 114-126.

Received February 25, 1997; accepted in revised form April 22, 1997. 


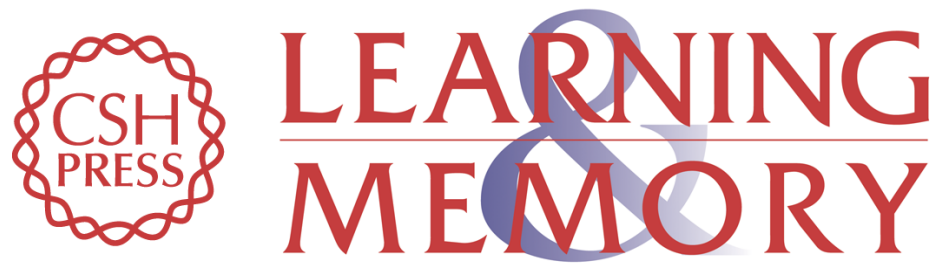

\section{Acquisition of a new-latency conditioned nictitating membrane response--major, but not complete, dependence on the ipsilateral cerebellum.}

C H Yeo, D H Lobo and A Baum

Learn. Mem. 1997, 3:

Access the most recent version at doi:10.1101//m.3.6.557

References This article cites 41 articles, 5 of which can be accessed free at: http://learnmem.cshlp.org/content/3/6/557.full.html\#ref-list-1

License

Email Alerting

Receive free email alerts when new articles cite this article - sign up in the box at the Service top right corner of the article or click here. 